\title{
XII. On the specific heats of gases
}

\section{Eilhard Wiedemann}

To cite this article: Eilhard Wiedemann (1876) XII. On the specific heats of gases, Philosophical Magazine Series 5, 2:9, 81-108, DOI: 10.1080/14786447608639169

To link to this article: http://dx.doi.org/10.1080/14786447608639169

$$
\text { 曲 Published online: } 13 \text { May } 2009 .
$$

Submit your article to this journal 전

Џll Article views: 2

Q View related articles ¿ 


\author{
AND \\ JOURNAL OF SCIENCE. \\ [FIFTH SERIES.]
}

$A \cup G U S T$

XII. On the Specific Heats of Gases, By Eilitard WredemanN* *

[Plate I.]

QINCE the publication of Régnault's work on the specific $\$$ heats of gases this subject has not, so far as I am aware, been experimentally dealt with. The apparatus required to carry out such investigations as those of Régnault is not usually at the command of many physicists.

I have sought to discover methods which would enable the experimenter to prosecute with exactness, yet with less complicated appliances, this inquiry, which has such important bearings upon the mechanical theory of heat and also upon molecular chemistry.

In the following first communication the methods of observation will be described, measurements of the specific heat of air will then be given, and, lastly, the relation between specific heat and temperature in the case of a few gases will be investigated $\dagger$.

In performing his measurements Régnault used an apparatus which consisted essentially of three parts-the vessel for storing the gas (gasometer), the heating-apparatus, and the calorimeter. Régnault's gasometer was of copper foil 5 millims. in thickness, and had a capacity of about 30 litres; the gas to be examined was compressed in it by means of a forcepump. Pressures varying from 3000 to 4000 millims. of

- From Pogg. Ann. der Physile und Chemie, vol. clvii. pp. 1-42. Tranolated by M. M. Pattison Muir, The Owens College, Manchester.

+ It need hardly be mentioned that Régnault has himself fully discussed the sources of error which may arise in his own methods of obserpation.

Phil. Mag. S. 5. Vol. 2. No, 9. Ang. 1876. 
mercury (at $0^{\circ} \mathrm{C}$.) were frequently employed; 9000 millims. was an attainable pressure. The gases could easily be sent through the warming-apparatus and calorimeter in sufficient quantity and with the necessary velocity. As the volume of the copper containing-vessel was known, the quantity of gas used could be calculated from the pressure existing before and after the experiment. That part of the apparatus in which the gases were warmed consisted of an oil-bath containing a tube of brass or platinum 8 millims. in width and 10 metres in length, through which the gas was allowed to flow. The calorimeter consisted of a similarly shaped spiral of thin sheettin surrounded with water. In taking an observation a known quantity of the gas under examination was allowed to flow through the warming-apparatus, which was heated to a determinate temperature; the heat thus absorbed was again given up to the water in the calorimeter; and from a determination of this quantity of heat the specific heat of the gas could be readily calculated.

In order to ensure, correct determinations, it was especially necessary that the gas should be completely heated to the temperature of the warming-apparatus, and that it should also entirely give up its heat in the calorimeter. The spiral through which the gas flowed was therefore required to present a considerable surface to the gas and thus to be of considerable length. This was the more requisite, inasmuch as the gas passed through the apparatus with a very considerable velocity, as much as 24 litres per minute. The length of the spiral necessitated that the vessel containing it should be of somewhat large dimensions. In the greater number of Régnault's researches the mass of water used amounted to 660 grms., calculated to the water-value of the spiral, the outer vessel, and the stirrer. In order to bring about a sufficient elevation of temperature in this mass of liquid, a large quantity of heated gas was necessarily employed.

The first problem to be solved appeared then to be how to diminish the size of the calorimeter and at the same time to allow the gas to give up all its heat-in other words, how to bring the heated gas into contact with the largest possible surface in the smallest possible space. For this purpose a method first made use of by Ericson in the construction of his airmachine was employed. It consisted in passing the gas over cupper gauze, which exposed a large surface for carrying away the heat.

Description of the Apparatus (Plate I.).

The heating-vessel consists of a copper box (hard-soldered), M, 20 centims. in height, 18 centims, in breadth, and 21 cen- 


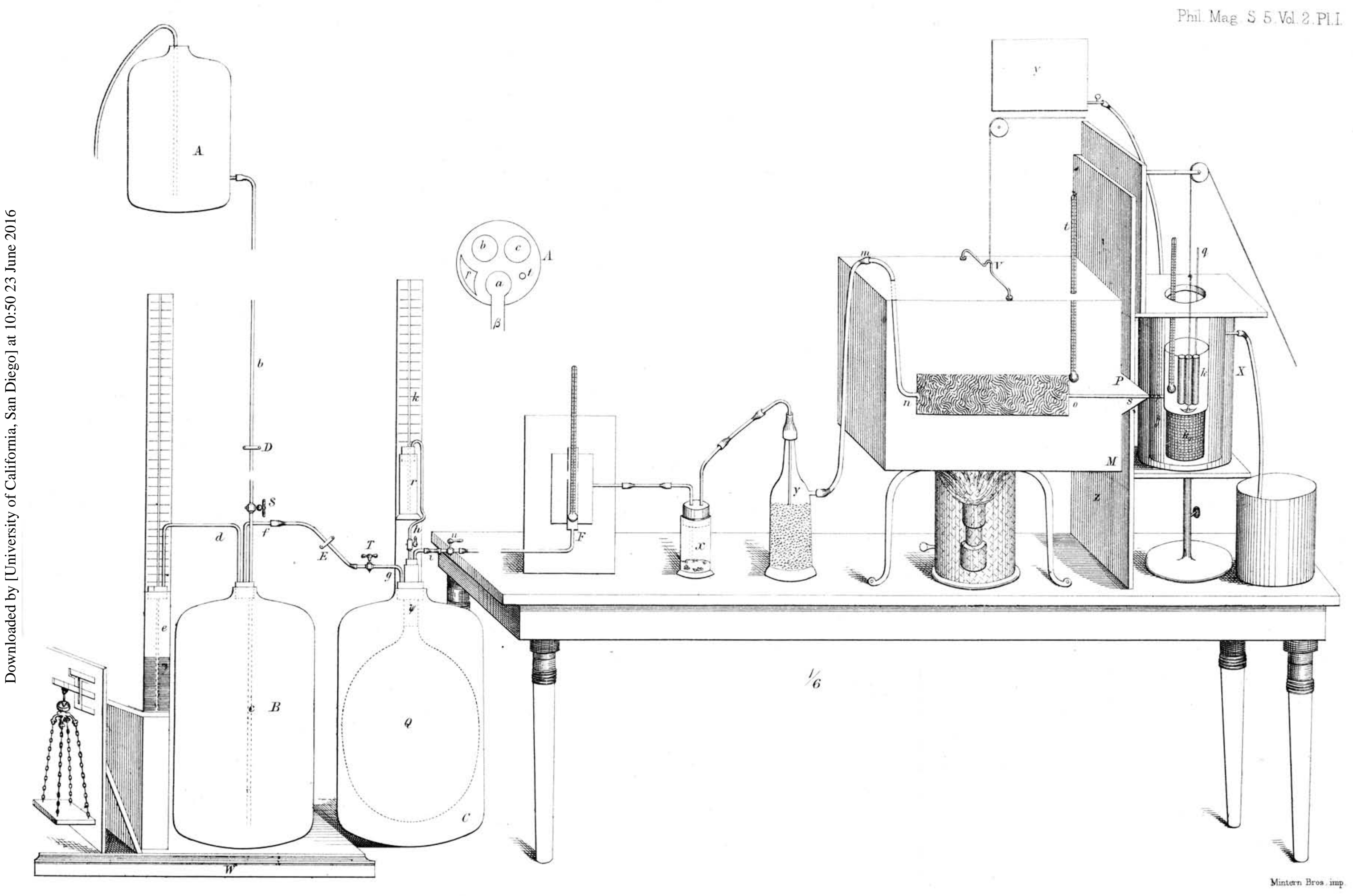


tims. in length, furnished with a funnel-shaped protuberance, $P$. In this box is placed the thin-walled copper cylinder, $G$, which has a length of 11 centims. and a diameter of 4 centims., and is filled with fine copper gauze. The gas enters by $m n$ and departs by o $p$. The latter tube is made of copper so far as $s$, from $s$ to $p$ it consists of German silver; it is 17 millims. in length. It was found that too much heat was conducted from the warming-vessel to the calorimeter if the exit-tube was made entirely of copper; the correction-constant, $k$ (to be discussed hereafter), received therefore too high a value. A thermometer passes through the lid of the heating-vessel. The liquid in the warming-vessel is constantly kept in motion by means of a stirrer, which consists of two perforated horizontal plates hard-soldered to a stirrup $\mathrm{V}$, and at a distance from one another somewhat greater than the breadth of the copper cylinder. A cord passing from $\mathrm{V}$ over a pulley is connected with clockwork, whereby the stirrer is raised twenty times per minute ; it falls again by its own weight. By an arrangement of sockets any liquid which might be carried up with the stirrer finds its way back into the warming-vessel. The temperature of the water (or paraffin) was regulated so that it did not vary more than, at the utmost, $1^{\circ}$ during the experiments.

The calorimeter $(k)$ consists of a silver vessel, outwardly of a cylindrical shape, $5 \frac{1}{2}$ centims. in height and 42 millims. in width, the thickness of the walls being 0.35 millim. Three vertical silver tubes, bound together by little horizontal tubes, are fused into the calorimeter; these serve for receiving the heat given up by the gas under examination. The gas enters through the tube $\beta$ placed horizontally 8.5 millims. from the bottom of the cylinder (this tube is 8 millims. in breadth); thence it pases to the first vertical tube, from the upper end of which it is conveyed to the next tube, and so on, finally making its exit by the narrow tube ( $2 \frac{1}{2}$ millims. wide) $q$. The individual tubes are 9 millims. in breadth and 41 millims. in height; they are all filled with silver gauze. Through a lid placed on the top of the vessel pass a thermometer, the stirrer, and the tube $q$. The bulb of the thermometer is placed between the first and third tube, the stirrer between the second and third.

Fig. A represents a section of the calorimeter at the level of the entering tube. $\beta$ is the tube by which the gas enters; $a, b$, and $c$ are the first, second, and third silver tubes respectively; $t$ is the thermometer, and $r$ is the stirrer. A small quantity of grease is introduced between the rim of the lid and the vessol to prevent the escape of the water which may be raised 
up in stiring. The warming-vessel and calorimeter are connected together by means of a cork, as was done by Régnault in his apparatus.

In order to maintain a constant temperature around the calorimeter during an experiment, the calorimeter is placed in a cylindrical vessel of sheet brass having two walls ; the height of this vessel is $17 \frac{1}{2}$ centims., and the diameter $14 \frac{1}{2}$ centims. A funnel-shaped orifice in the front part of this vessel allows of the introduction of the tube $\beta$ without contact between the two. By means of the side tubes water, maintained at uniform temperature, is allowed to circulate through this vessel. A wooden partition covered with tinfoil, $z$, and furmished with a circular opening in the centre, protects the vessel just described from the heat radiated from the warming-apparatus. The calorimeter is supported in a wicker stand in the centre of the brass vessel $\chi$. A board covered with tinfoil is placed on the top of $\chi$; and to this board another, protected in the same manner, is vertically attached.

The latter carries a pulley, over which passes the cord attached to the stirrer of the calorimeter; the stirrer is moved upwards and downwards 40 to 50 times per minute.

The thermometer of the calorimeter is illuminated from behind by means of a gas-lamp, the heat-rays from which are cut off by the interposition of four glass plates. Immediately behind the thermometer is placed a glass plate covered, with the exception of a space equal to the breadth of the thermometer, with tinfoil ; by means of this arrangement foreign light is cut off.

The thermometer employed was graduated to tenths of a degree; by using a telescope it could be read to hundredths of a degree. This thermometer was calibrated and carefully compared with a standard from $0^{\circ}$ to $40^{\circ}$.

On account of the size of the apparatus and the great pressures required, Régnault's method of storing and delivering the gases, and of measuring their volumes, could not be employed. It was, however, found possible to modify the method of Belaroche and Bérard so as to obtain exact results. These experimenters forced the gases from moist animal bladders, which were placed in a balloon communicating with another into which water issued at a constant velocity. From the quantity of water entering, the quantity of gas issuing could be be calculated. By replacing the animal membrane by caoutchouc, the gases could be maintained free from moisture.

The apparatus which I enploy has the following disposition:-A large glass balloon (C) is closed air-tight by means 
of a caoutchouc stopper. Two glass tubes, a wider $(\psi)$ and a narrower $(g)$, pass through this stopper. A balloon of thick black caoutchouc, Q, holding about 20 litres of gas, is connected with the wider tube $\psi$, which is closed by means of a caoutchouc stopper carrying two tubes- $i$ leading to the heating-apparatus, and the other, leading to the manometer, $k$. The manometer consists of a glass, $r$, into which the graduated tube $k$ is fastened air-tight. By means of the stopcock $h$, communication can be made or broken between $Q$ and the manometer. Very wide stopcocks, $\mathrm{T}$ and $\mathrm{V}$, are placed on the tubes $g$ and $i$.

The second balloon, $\mathrm{B}$, besides communicating with $\mathrm{Q}$, is fitted with two holes-one leading to the manometer, $e$, the other passing to the bottom of the vessel, and capable of being brought into connexion by means of the stopcock $S$ with the water-cistern $A$. The tubes establishing communication between $\mathrm{B}$ and $\mathrm{C}$ are so wide that the pressure in each will not alter during the escape of gas from $Q$.

The manometers $e$ and $k$ contain water ; the smallest variations in pressure can therefore be easily read off without the use of a cathetometer. Inasmuch as communication between $Q$ and $r$ is made by means of a tube 40 centims. in length and bent many times, and also inasmuch as each experiment only lasts for a short time, the wetting of the gas in the balloon $Q$ is not to be feared.

$B$ stands upon $a$ bridge-balance, by means of which the weight of this balloon can be ascertained to within $5 \mathrm{grms}$. with certainty. The gas escaping from $Q$ is sent through an apparatus $\mathrm{F}$, consisting of two tubes so connected together that the gas passes through the inner, then gives up its heat to a thermometer, and finally passes on through the outer tube. These tubes are placed in a wooden case. The temperature possessed by the gas issuing from $Q$ is thus ascertained. By causing the gas to bubble through a cylinder filled with sulphuric acid or with mercury, $x$, the rate at which it is flowing is noticed. The apparatus $y$ is filled with little glass beads, and serves to retain any sulphuric acid which may have been mechanically carried over from $x$.

Before carrying out determinations of the specific heats of gases with the apparatus just described, it was necessary to ascertain with certainty whether or not the temperature of the gas as it issued from the heating-vessel was really the same as that of the liquid in the vessel. For this purpose an apparatus similar to that employed for determining the temperature of the gas before it entered the heating-vessel was placed in connexion with the German-silver tube leading 
from the heating-vessel. When 10 litres of gas were passing through the apparatus per minute the thermometer remained constant at $100^{\circ}$.

Another method for determining that the gases are thoroughly warmed has been proposed by Régnault. $\mathrm{He}$ placed a thermometer in the anterior part of the spiral of the heating-vessel. This method is open to the objection that the thermometer is exposed to the influence of the heat radiated from the sides of the apparatus. A gas which has only cooled slightly will therefore produce an extremely small effect on the indication of the thermometer.

In order to ascertain whether the heated gas entirely parted with its heat in the calorimeter, experiments were carried out with a similarly constructed instrument, in which the three tubes filled with silver were replaced by two tubes filled with copper; the numbers representing the specific heats were identical within the limits of experimental error. It was also determined that the heat was entirely given up during the passage of the gas through the first tube; when one of the tubes only was filled with copper gauze and a thermometer surrounded with gauze was placed in the second tube, the temperature indicated by the thermometer was almost identical with that of the surrounding liquid. By using three tubes no doubt could arise as to whether the heat was entirely given up in the calorimeter.

Even if the gas did not enter and leave the calorimeter at the exact temperature indicated by the thermometer in the heating-vessel and in the calorimeter respectively, the result of the experiments would be but very slightly affected thereby, inasmuch as the total cooling of the gas is represented by the difference between these two temperatures, and this difference always amounts to at least $75^{\circ} \mathrm{C}$.

\section{Method of Observation.}

In carrying out the measurements the following was the method of procedure :-

The balloon $Q$, after having been entirely emptied, was filled with the gas to be examined, the gas being pure and dry.

For this purpose the balloons $\mathrm{B}$ and $\mathrm{C}$ were disconnected, and the stopcocks $T$ and $V$ were opened. In order that the gas should enter $Q$ at a fixed temperature, it was caused to traverse a cylinder filled with copper gauze and surrounded with water, which was maintained at the temperature of the air of the room.

The thermometer (F) was arranged so as to indicate the 
temperature of the gas as it entered the balloon. The time allowed to elapse between the filling of $Q$ and the carryingout of the experiment never exceeded half an hour ; in this short time the temperature of the surroundings and of the gas itself altered but slightly ; the thermometer $\mathrm{F}$ indicated very nearly the true temperature of the gas in the balloon as that gas for the second time passed over its surface.

When a new gas was to be examined, the balloon $Q$, having been emptied, was only partially filled with this gas and again emptied before being finally filled; in this way the last traces of the gas originally in the balloon were removed.

In filling $Q$ the gas was allowed to stream through until the walls of the balloon were stiffy distended. On account of their weight the walls of the balloon then pressed upon the contained gas with a force equal to 1 centim. of water, as determined by the manometer $k$.

The stopcock $\mathrm{V}$ being closed the calorimeter was connected in its place. $\mathrm{B}$ and $\mathrm{C}$ were connected and the pinchcock $\mathrm{E}$ was removed; $b$ and $c$ in the balloon $\mathrm{B}$ were then connected, $D$ was removed, and water was allowed to flow from $A$ until the manometers $k$ and $e$ showed the pressure at which the gas was to be allowed to issue from $Q$.

$\mathrm{S}$ having been then closed, $\mathrm{D}$ and $\mathrm{E}$ replaced, and $\mathrm{A}$ and $\mathrm{B}$ and $\mathrm{B}$ and $\mathrm{C}$ disconnected, the balloon was weighed in the balance $\mathrm{W}$. A, B, and C were then once more connected, D and $\mathrm{E}$ were again removed, and $\mathrm{T}$ was opened; $\mathrm{S}$ and $\mathrm{V}$ remained meanwhile closed.

The temperature of the calorimeter was noticed as the apparatus was placed in position. The telescope, through which the temperature of the calorimeter was read off, was so placed that one could look through it and at the same time open the stopcocks V and S with the hand.

The position of the thermometer in the calorimeter was read off from minute to minute. Five or ten minutes after the beginning of the experiment $V$ and $S$ were opened at the same moment (marked by means of a second stop-watch), and the gas was allowed to flow through the heating-vessel and calorimeter. By carefully regulating the stopcock $\mathrm{S}$ the manometers $k$ and $e$ could be readily maintained constant; the gas in $Q$ was therefore maintained at the same pressure throughout the experiment, and consequently flowed through the calorimeter at a constant rate. The temperature of the calorimeter was determined each minute as the gas passed through it. So soon as the rise of temperature had attained to a certain amount (between $5^{\circ}$ and $12^{\circ}$ ), the flows of gas and of water into B were simultaneously checked by suddenly 
closing $V$ and $S$, and the watch was read off. Then the temperatures were noted for five to ten minutes-at first each second, afterwards from minute to minute. A regular increase of temperature occurred generally at the tenth and twentieth seconds after closing the stopcocks; so short was the time required for the temperature of the silver gauze to become equalized with that of the water of the calorimeter. The time was longer the higher the temperature of the entering gas, inasmuch as the gauze situated nearest to the entranceaperture underwent a greater rise in temperature. Immediately before and after the experiment the temperature of the heating-vessel was determined, the mean of the two readings being taken as the temperature during the experiment.

Water maintained at the temperature of the air of the room flowed continuously through the double-walled vessel $\chi$. The temperature of this water was determined before it entered and when it flowed from $x$. Notwithstanding the wooden screen, a slight increase in the temperature of the water was observed; the mean of the two readings was adopted.

$A, B$, and $C$ being again disconnected, $B$ was reweighed; it had increased by the amount of water which had entered it.

Inasmuch as temperature and pressure remained constant in $B$ and $C$ during the experiment, the volume of water (calculated from the weight) which had entered $B$ expressed the volume of gas which had flowed from $Q$. It did not signify whether diffusion had occurred through the caoutchouc balloon or not; if this did occur, it could only somewhat decrease the purity of the gas. It was directly shown by experiment (using carbonic acid and ammonia) that the gas in $Q$ became mixed with but traces of air. Although the water did not possess the temperature of $4^{\circ} \mathrm{C}$., the error arising from this appeared so small as not to necessitate the use of a correction.

In order to calculate the weight of the issuing gas, it was necessary that its temperature and pressure should be known. The former was obtained, as has been already described, by reading off the thermometer $F$. The latter was composed of two parts-of the atmospheric pressure, and of the pressure indicated by $k$. If the barometer-reading reduced to $0^{\circ}$ be represented by $\mathrm{B}$, the reading of the manometer $k$ reduced to mercury be $p$, the temperature of the gas be $x$, and the observed volume of the gas be $v$, then the calculated volume at $0^{\circ}$ and 760 millims. pressure is

$$
v_{0}=\frac{p+\mathrm{B}}{760} \cdot \frac{273 \cdot 2}{27 \overline{3 \cdot 2}+x} v .
$$

If a represent the specific gravity of the gas referred to air, 
then, as the specific gravity of air at $0^{\circ}$ and 760 milims. referred to water is $\frac{1}{773 \cdot 3}$, the weight of volume $v$ of the. gas is

$$
\mathrm{G}=\frac{v_{0} \sigma \cdot 1}{773 \cdot 3}=\frac{p+\mathrm{B}}{760} \cdot \frac{273 \cdot 3 \cdot \sigma}{(273 \cdot 3+x)} \cdot \frac{v}{773 \cdot 3}
$$

Lastly, if $W$ represents the weight in kilos of water which entered the balloon during the experiment, and if the litre be taken as unit of volume, then

$$
\mathrm{G}=\frac{p+\mathrm{B}}{760} \cdot \frac{273 \cdot 3 \cdot \sigma}{(273 \cdot 3+x)} \cdot \frac{\mathrm{W}}{773 \cdot 3} .
$$

In order to calculate the specific heat, we require also the weight of liquid in the calorimeter, as also the water-value of the calorimeter. The weight of liquid was determined by direct weighing before every experiment ; it varied from 59 to $61 \mathrm{grms}$. The water-value of the calorimeter was calculated. The specific heat of the silver used for making the vessel was 0.0607 ; its weight amounted to 80.122 grms.; the water-value was therefore 5.07. The water-value of that part of the thermometer which was situated in the calorimeter, and which was measured, amounted to $0 \cdot 3944$. The total watervalue of the calorimeter was therefore $5 \cdot 4644$. A small error in the estimation of the water-value of the thermometer would not greatly influence the final result, because of the smallness of the total figure.

The rise of temperature observed by means of the thermometer in the calorimeter must not be attributed solely to the heat given up by the gas, and cannot be directly used for calculating the specific heat of the gas; but a correction must be applied, partly because of heat conducted through the Germansilver tube from the heating-vessel, and partly because of heat radiated to or from the calorimeter.

By passing air at the same velocity as was done with the various gases through the calorimeter (surrounded with water at the temperature of the air), it was proved that no appreciable amount of heat is generated by friction of the particles of gas against the silver gauze in the calorimeter.

We assume that the amount of heat gained by the calorimeter by conduction is constant for each unit of time during the whole experiment*; and we designate the rise of temperature per minute caused by this heating of the calorimeter by $k$.

* Régnault, Relation des experiences pour déterminer les lois et les donnecs physiques nécessaires au calcul des Machines-ri-feu, p. 79 et seq. 
In order to estimate the heat radiated to and from the calorimeter, as also that carried away by currents of air, we make the assumption (justified by the smallness of the differences of temperature) that this is proportional to the difference of temperature between the calorimeter and its surroundings. We shall designate the rise of temperature per minute brought about by radiation \&c., for a temperature-difference of $1^{\delta}$ between calorimeter and surroundings, by $\alpha$. The measurements taken before and after the gas was allowed to flow through the apparatus serve as data for calculating the values of $\alpha$ and $k$.

Let $\mathrm{T}$ represent the mean temperature of the calorimeter during the initial period, $\mathrm{T}_{1}$ the mean temperature during the final period; let $\tau$ represent the temperature of the surroundings ; $m$ and $m_{1}$ the increase of temperature of the calorimeter per minte during these periods ; then

bence we deduce

$$
\begin{aligned}
& -(\mathrm{T}-\tau) \alpha+k=m, \\
& -\left(\mathrm{T}_{1}-\tau\right) \alpha+k=m_{1} ;
\end{aligned}
$$

$$
\alpha=\frac{m-m_{1}}{\mathrm{~T}_{1}-\mathrm{T}}
$$

and

$$
k=m+\frac{(\mathrm{T}-\tau)\left(m-m_{1}\right)}{\mathrm{T}_{1}-\mathrm{T}} .
$$

It may readily be shown that it is not really necessary to know the temperature of the surroundings (that is, the value of $\tau$ ), inasmuch as it remains constant throughout the experiment.

For this purpose let us suppose that the rise of temperature is uniform so long as gas passes through the calorimeter (and with a constant flow of gas this is almost exactly true), and let us calculate, on this supposition, the mean correction which it is necessary to apply to the observed temperature for each minute of time.

Let the temperature of the calorimeter at the moment when the gas begins to pass through be represented by $t_{1}$, and at the moment of closing the stopcock by $t_{2}$. Then the mean temperature during the experiment is

The correction is then

$$
\frac{t_{1}+t_{2}}{2}
$$

$$
-\alpha\left\{\frac{t_{1}+t_{2}}{2}-\tau\right\}+k
$$


and by substituting the values of $\alpha$ and $k$ we get

$$
\begin{aligned}
& -\frac{m-m_{1}}{\mathrm{~T}_{1}-\tau}\left\{\frac{t_{1}+t_{2}}{2}-\tau\right\}+m+\frac{(\mathrm{T}-\tau)\left(m-m_{1}\right)}{\mathrm{T}_{1}-\mathrm{T}}=\mathrm{C}, \\
& m-m_{1} \\
& \frac{m-\mathrm{T}}{\mathrm{T}_{1}-\mathrm{T}}+m-\frac{m-m_{1}}{\mathrm{~T}_{1}-\mathrm{T}} \frac{t_{1}+t_{2}}{2}+\frac{\mathrm{T}\left(m-m_{1}\right)}{\mathrm{T}_{1}-\mathrm{T}}-\tau \frac{m-m_{1}}{\mathrm{~T}_{1}-\mathrm{T}}=\mathrm{C},
\end{aligned}
$$

an equation in which the two terms containing $T$ cancel one another. The correction is therefore independent of the temperature of the surroundings, $\tau$.

The correction necessitated by the fact that the whole of the mercury of the thermometer was not surrounded by liquid must, of course, be applied to the temperatures $t$ and $t_{1}$.

The temperature indicated by the thermometer ten seconds after closing the stopcocks was taken to be $t_{1}$ : a part at least of the increase of temperature noticed during this short period must be traced to the fact that the thermometer and its surroundings, as also the silver gauze, did not possess the same temperature as the liquid of the calorimeter. Nevertheless the result is unaffected, whether we choose for $t_{1}$ this temperature or that indicated at the moment of closing the stopcocks.

We must now estimate the cooling of the gases. If $\mathrm{M}$ represent the constant (mean) temperature of the heating-vessel during the experiment, then the cooling is represented by

$$
\Theta=\mathrm{M}-\frac{t_{1}+t_{2}}{2} \text {. }
$$

But if $W$ be the weight of water in the calorimeter added to the water-value of the same, $G$ the weight of the gas, $\theta_{1}$ the corrected temperature-increase of the calorimeter, and $\mathrm{C}$ the specific heat of the gas under examination, then

also

$$
\text { W. } \theta_{1}=c \mathrm{G} \Theta
$$

$$
c=\frac{W \theta_{1}}{G \Theta} \text {. }
$$

By multiplying the specific heats by the densities of the gases, referred to air, we obtain the specific heats of equal volumes of the different gases, if that of air be taken, for unit volume, as equal to 0.2389 ; that is, we obtain so-called relative heats.

In order to determine the influence of temperature upon the specific heats of the different gases, they were heated once to $100^{\circ}$ and another time to $200^{\circ}$, and the mean specific heat estimated between this temperature $t$ and the temperature $\tau$ $\left(20-25^{\circ}\right)$ of the liquid in the calorimeter. If we represent by $Q$ the amount of heat which must be given up to the gas in order to raise its temperature from $\tau^{\circ}$ to $t^{\circ}, Q$ may be repre- 
sented as a function of the temperature by the equation where $a$ and $b$ are constants.

$$
\mathrm{Q}=a(t-\tau)+b(t-\tau)^{2}
$$

If, however, $c_{1}$ is the mean specific heat between $\tau^{\circ}$ and $100^{\circ}$, $c_{2}$ that between $\tau^{\circ}$ and $200^{\circ}$, then $t=100$ in one case, and in the other $=200$, and then $Q$ is equal to the mean specific heat $c$ multiplied by the temperature-increase; so we have

$$
\begin{aligned}
& \mathrm{Q}=c(t-\tau), \\
& c_{1}=(100-\tau)=a(100-\tau)+b(100-\tau)^{2}, \\
& c_{2}=(200-\tau)=a(200-\tau)+b(200-\tau)^{2},
\end{aligned}
$$

or

$$
\begin{aligned}
& c_{1}=a+b(100-\tau), \\
& c_{2}=a+b(200-\tau),
\end{aligned}
$$

equations from which $a$ and $b$ may be immediately deduced. But the specific heat is the change in the quantity of heat contained in unit weight of the body for unit of temperature, i.e.

$$
\frac{d \mathrm{Q}}{d t} \text {. }
$$

For the true specific heat at temperature $t$ it follows that

$$
\mathrm{C}=a+2 b(t-\tau)
$$

from which we can directly deduce the relative heats.

In the following Tables the observed and calculated results of the determinations of specific heats of various gases made in accordance with the methods described above are recorded. In those Tables, -

$W$ represents the weight of water in the calorimeter ;

$G$ the weight, in kilogrammes, of water entering the balloon, and the volume, in litres, of the gas flowing from the balloon ;

B the barometric pressure;

$p$ the pressure read off on the manometer $k$;

$\chi$ the temperature of the gas in the caoutchouc balloon;

$n$ the duration of the experiment, in minutes ;

$a$ the volume of gas passing from the balloon per minute;

$\tau$ the temperature of the surroundings;

$\mathrm{T}$ the mean temperature of the calorimeter during the initial period;

$m$ the rise of temperature of the calorimeter in each minute of the initial period;

$\mathrm{T}_{1}$ the mean temperature of the calorimeter during the final period;

$m_{1}$ the rise of temperature of the calorimeter in each minute of the final perion; 
M. E. Wiedemann on the Specific Heats of Gases.

$k$ and $\alpha$ the constants discussed on p. 90 ;

$\theta$ the observed temperature-increase of the calorimeter ;

$\theta_{1}$ the corrected temperature-increase of the calorimeter ;

$t$ the mean temperature of the calorimeter;

$M$ the temperature of the heating-vessel ;

$A$ the temperature-decrease of the gas;

$c$ the specific heat of the gas.

\section{Air.}

The air coming from a gasometer was dried by passing through sulphuric acid in a Woulfe's bottle, and through a cylinder containing beads soaked in sulphuric acid.

\begin{tabular}{|c|c|c|c|c|c|c|}
\hline & 1. & 2. & 3. & 4. & 5. & 6. \\
\hline \multirow{16}{*}{ 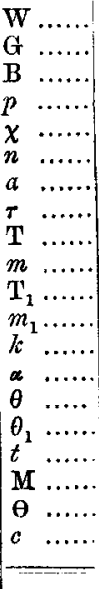 } & & & & $59 \cdot 96$ & 61 & $58 \cdot 41$ \\
\hline & $\begin{array}{r}15.56 \\
759 \cdot 9\end{array}$ & $20 \cdot 32$ & & $26 \cdot 13$ & $17 \cdot 43$ & \\
\hline & $\begin{array}{c}76.9 \\
75 \cdot 08\end{array}$ & $\begin{array}{r}760 \\
62\end{array}$ & $\begin{array}{c}761 \cdot 3 \\
60 \cdot 80\end{array}$ & $\begin{array}{r}760 \cdot 3 \\
60 \cdot 4\end{array}$ & $\begin{array}{r}758 \cdot 7 \\
56 \cdot 70\end{array}$ & \\
\hline & $15 \cdot 6$ & 16 & $16: 8$ & 17 & 164 & $16 \cdot 4$ \\
\hline & $3 \frac{1}{2}$ & 5 & & & & 4 \\
\hline & $4 \mathbf{4 3}$ & $4 \cdot 06$ & 3.93 & 4.03 & 387 & $4 \cdot 44$ \\
\hline & 15.8 & $16 \cdot 2$ & $17 \cdot$ & $17 \cdot 2$ & 16. & \\
\hline & $\begin{array}{c}14.46 \\
0.0604\end{array}$ & $\begin{array}{c}15 \cdot 22 \\
0 \cdot 064\end{array}$ & $\begin{array}{c}16 \cdot 38 \\
0.088\end{array}$ & $\begin{array}{r}16 \cdot 85 \\
0.06\end{array}$ & $\begin{array}{c}15 \cdot 61 \\
0.072\end{array}$ & $\begin{array}{c}16 \cdot 23 \\
0.0675\end{array}$ \\
\hline & $21 \cdot 07$ & $23 \cdot 26$ & $23 \cdot 71$ & $24 \cdot 635$ & $22 \cdot 60$ & 23.51 \\
\hline & -0.013 & -0.03 & $0 \cdot 00$ & $-0 \cdot 032$ & $0 \cdot 0025$ & -0.026 \\
\hline & $\begin{array}{l}0.0 \\
0.0\end{array}$ & $\begin{array}{l}0.0526 \\
0 \cdot 0117\end{array}$ & $\begin{array}{l}0 \cdot 0780 \\
0.012\end{array}$ & $\begin{array}{l}0.056 \\
0.0118\end{array}$ & $\begin{array}{l}0.0 \\
0.0\end{array}$ & $\begin{array}{l}0.059 \\
0.013\end{array}$ \\
\hline & 6.48 & 7.95 & $7 \cdot 1$ & 7.8 & $6 \cdot 75$ & $7 \cdot 13$ \\
\hline & $6 \cdot 39$ & $7 \cdot 85$ & 6.9 & $7 \cdot 74$ & 6.61 & $7 \cdot 06$ \\
\hline & 1786 & $19 \cdot 42$ & $20 \cdot 15$ & 209 & $19 \cdot 22$ & $20 \cdot 06$ \\
\hline & $100^{\circ}$ & $100^{\circ}$ & $100^{\circ}$ & $100^{\circ}$ & $100^{\circ}$ & \\
\hline & $\begin{array}{c}82 \cdot 14 \\
0 \cdot 2389\end{array}$ & \begin{tabular}{|c|}
80.58 \\
0.2395
\end{tabular} & $\begin{array}{c}79 \cdot 85 \\
6 \cdot 2413\end{array}$ & $\mid \begin{array}{l}79 \cdot 1 \\
0 \cdot 2414\end{array}$ & $\begin{array}{c}80 \cdot 78 \\
0.2376\end{array}$ & $\begin{array}{l}79 \cdot 74 \\
0 \cdot 2398\end{array}$ \\
\hline & 7 & 8. & $\mathbf{y}$ & 10. & 11. & 12 \\
\hline & & & & & & \\
\hline & $18 \cdot 2$ & & & & & \\
\hline & $755 \cdot 26$ & $755 \cdot 26$ & 751 & $751^{\circ}$ & $745 \cdot 7$ & $745 \cdot 7$ \\
\hline$p$. & $55 \cdot 0$ & 84 & & & & 76 \\
\hline$\cdots$ & $16 \cdot 8$ & $16 \cdot 8$ & & 17 & $21 \cdot 5$ & 22 \\
\hline$\ldots$ & 5 & $3 \frac{1}{3}$ & $3 \frac{2}{3}$ & $3 \frac{2}{8}$ & 35 & $3 \frac{3}{4}$ \\
\hline$a \quad \ldots .$. & $3 \cdot 64$ & $4 \cdot 73$ & 4.42 & & $4 \cdot 7$ & $4 \cdot 65$ \\
\hline$\tau$ & 17 & 17 & 16 & 17 & 21.2 & $22 \cdot 2$ \\
\hline$T$ & $16 \cdot 72$ & 170 & & & 20 & $19 \cdot 63$ \\
\hline$m$ & 0.073 & & & & $0 \cdot 0$ & \\
\hline & $23 \cdot 82$ & 23.8 & & $23 \cdot 7$ & & \\
\hline$m_{1} \ldots \ldots$ & -0.01 & -0.096 & -0.003 & -0.003 & -0.02 & +0.021 \\
\hline & 0.0702 & & & 0.0695 & & \\
\hline$a \ldots$. & $0 \cdot 0$ & 0.01 & 0.0128 & $0 \cdot(1117$ & 0.0154 & 0.011 \\
\hline & $6 \cdot 9$ & & $6 \cdot 46$ & $6 \cdot 86$ & $6 \cdot 62$ & $6 \cdot 71$ \\
\hline$\theta_{1}$ & $6 \cdot 7$ & 6.42 & $6 \cdot 32$ & $6 \cdot 72$ & $6 \cdot 50$ & $6 \cdot 49$ \\
\hline & $20 \cdot 4$ & $20 \cdot 63$ & & $20 \cdot 30$ & $23 \cdot 6$ & $\mathbf{2 3 \cdot 2 4}$ \\
\hline & $99 \cdot 8$ & & $99 \cdot 7$ & 99 & $100 \cdot 9$ & 102 \\
\hline & $79 \cdot 4$ & $79 \cdot 17$ & $80 \cdot 37$ & $79 \cdot 4$ & $77 \cdot 3$ & 78.76 \\
\hline & & & & $0 \cdot 2407$ & 0.2374 & \\
\hline
\end{tabular}


The mean value is 0.2389 , the greatest deviation from this being 0.0025 .

Experiments Nos. 9 and 10 were carried out four weeks after Nos. 1 to 8 , and Nos 11 and 12 some time after 9 and 10 ; during the earlier experiments the heating-vessel contained boiling water; during the two latter experiments it contained melted paraffin.

The numbers agree among themselves to as great an extent as do those obtained by Régnault : thus he obtained numbers varying from $0 \cdot 23536$ to $0 \cdot 23890$; my numbers vary from 0.2374 to 0.2414 . The mean number 0.2389 obtained by me differs by less than 1 per cent. from that obtained by Régnault, viz. $0 \cdot 23751$.

The method adopted for graduating the thermometer for $150^{\circ}$ and $200^{\circ}$ may fitly be described in connexion with the specific heat of air.

In order to determine the temperatures which corresponded, in an air-thermometer, to the 150th and 200th degree of the thermometer used in the heating-vessel, the paraffin-bath was heated steady until the mercury column reached and remained steadfast at the given degree. The process, as if for determining the specific heat of air, was then proceeded with; and the lowering of temperature of the air of the calorimeter was calculated from the known specific heat of air (which, as shown by Régnault, is independent of temperature) and from the other data of the experiment.

By adding this lowering of temperature to the mean temperature of the liquid in the calorimeter during the experiment, which corresponds with the final temperature of the air after cooling, the initial temperature of the air was obtained, and therewith also the temperature measured by an air-thermometer which corresponded with the position of the thermometer. The differences of the calculated deviations of our thermometers from an air-thermometer are of the same order as those occurring in the estimation of specific heat itself.

\section{Hydrogen.}

The hydrogen was prepared from zinc and dilute sulphuric acid in a Kipp's machine, purified by passing through caustic potash, and dried by means of sulphuric acid. The following Table expresses the mean specific heats obtained for hydrogen between $100^{\circ}$ and $20^{\circ}$. 


\begin{tabular}{|c|c|c|c|c|c|c|}
\hline & 1. & 2. & 3. & 4. & 5. & 6. \\
\hline & & & 6 & $60 \cdot 10$ & & $60 \cdot 18$ \\
\hline G & $19 \cdot 1$ & & & & & \\
\hline & $751 \cdot 09$ & 751 . & 75 & & 759 & 759 \\
\hline$p \quad \ldots$ & $26 \cdot 70$ & $26 \cdot 52$ & $19 \cdot 1$ & 25 . & & $20 \cdot 4$ \\
\hline & $17 \cdot 80$ & $18 \cdot 20$ & 18.20 & & & 18 \\
\hline$\cdots$ & $2 \frac{5}{8}$ & $2 \frac{1}{2}$ & $3_{\frac{1}{2}}$ & $2 \frac{3}{4}$ & $3 \frac{1}{2}$ & 4 \\
\hline$\tau$ & $17^{\circ} \cdot 4$ & $17 \cdot 80$ & 18.00 & 18.7 & $17 \cdot 1$ & 18.2 \\
\hline & $5 \cdot 77$ & 6.70 & $5 \cdot 13$ & $6 \cdot 43$ & $5 \cdot 26$ & $4 \cdot 44$ \\
\hline & 16.80 & $18 \cdot 00$ & $18:$ & 18 & 17 & 16.60 \\
\hline$m$ & $0 \cdot 10$ & & 0.0 & & 57 & 8 \\
\hline$T_{1}$. & $24 \cdot 00$ & $24 \cdot 54$ & $25 \cdot 4$ & 24 . & & \\
\hline$m_{1} \ldots$ & $0 \cdot 04$ & $0 \cdot 05$ & 0.02 & 0.022 & -0.018 & -0.004 \\
\hline & 0.095 & $0 \cdot 1084$ & $0.09 \cdot 2$ & 0.0982 & $0 \cdot 066$ & 0.0617 \\
\hline$\alpha$ & $0 \cdot 0083$ & 0.00764 & 0.0097 & 0.0123 & $0.019 i$ & 0.0114 \\
\hline & 6.80 & 6.005 & & & & 6.52 \\
\hline$\theta_{2} \ldots$. & $6 \cdot 62$ & $5 \cdot 82$ & 6.02 & $6 \cdot 134$ & 6.632 & $6 \cdot 38$ \\
\hline & $20 \cdot 40$ & $21 \cdot 30$ & $22 \cdot 30$ & $21 \cdot 63$ & $21 \cdot 05$ & $20 \cdot 14$ \\
\hline & $99 \cdot 70$ & $99 \cdot 70$ & $99 \cdot 80$ & $99 \cdot 80$ & 100 & 100 \\
\hline & $79 \cdot 30$ & $78 \cdot 4$ & $77:$ & $78 \cdot 17$ & & \\
\hline & $\mathbf{3 3 3 6}$ & $3 \cdot 384$ & $\mathbf{3} 333$ & $3 \cdot 371$ & $3 \cdot 413$ & $3 \cdot 406$ \\
\hline
\end{tabular}

The mean number deduced from experiments 5 and 6 is $3 \cdot 410$, the greatest deviation therefrom being $0 \cdot 004$. The fact that the first four numbers are larger than the last two is explained by Régnault's observation that the constant $k$ acquires a larger value when the whole apparatus is filled with hydrogen (as was the case in the first four experiments) than when it is filled with air. When the very mobile hydrogen is allowed to remain at rest before and after the experiments, currents are engendered which carry over heat from the heating-vessel to the calorimeter, without taking into account the heat conducted from the German-silver tube. But in making the correction, the heat conducted over is alone taken into account, when the apparatus is filled with a stream of gas, as the secondary currents are then entirely neutralized. But too great a value for $k$ causes the negative correction for the observed temperatureincrease to be also too large, and therefore the temperatureincrease itself to be too small. The smallness of the number obtained for the specific heat is thus accounted for.

In the last two experiments the apparatus was filled with air before and after each experiment; $k$ has in these cases the smaller and more correct value, and the number 3.410 then obtained for the specific heat of hydrogren agrees well with Régnault's number $3 \cdot 409$, especially when it is remembered that his numbers vary from $3 \cdot 401$ to $3 \cdot 419$.

By multiplying 0.9692 by 3.410 the number 0.2358 is obtained as representing the specific heat referred to volume.

It did not appear to be of interest to determine the specific 
heat of hydrogen at varying temperatures, inasmuch as Régnault has shown that in the case of this gas the specific heat is independent of the temperature. Neither did an examination of oxygen or of nitrogen appear to be necessary. Régnault has shown that the specific heat of the first, referred to volume, is the same as that of air ; the same must therefore hold good for nitrogen. Inasmuch also as air exhibits no change of specific heat with change of temperature, we must believe that neither is there any change in the case of its constituents.

\section{Carbonic Acid.}

The carbonic acid was generated in a Kipp's apparatus from marble and dilute hydrochloric acid. It was purified from traces of hydrochloric acid by passing through a solution of sodium bicarbonate, and was then dried by means of sulphuric acid. The carbonic acid employed never contained more than from $\frac{1}{2}$ to 1 per cent. of air when examined after coming from the balloon.

The following Table contains the results of the experiments.

TABLE I.-Experiments between $100^{\circ}$ and $20^{\circ}$ to $25^{\circ}$.

\begin{tabular}{|c|c|c|c|c|c|c|c|c|c|}
\hline & 1. & 2. & 3. & 4. & 5 . & 6. & 7. & 8. & 9. \\
\hline 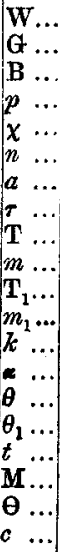 & \begin{tabular}{|c}
$59 \cdot 84$ \\
$15 \cdot 13$ \\
$755 \cdot 90$ \\
$17 \cdot 70$ \\
$86 \cdot 10$ \\
$4 \frac{1}{3}$ \\
$3 \cdot 36$ \\
$18 \cdot 100$ \\
$17 \cdot 10$ \\
$0 \cdot 075$ \\
$25 \cdot 24$ \\
$-0 \cdot 023$ \\
$0 \cdot 0642$ \\
$0 \cdot 0121$ \\
$7 \cdot 92$ \\
$7 \cdot 81$ \\
$21 \cdot 36$ \\
$99 \cdot 80$ \\
$78 \cdot 44$ \\
$0 \cdot 2084$ \\
\end{tabular} & \begin{tabular}{|c}
$59 \cdot 15$ \\
$15 \cdot 12$ \\
$755 \cdot 43$ \\
$16 \cdot 60$ \\
$66 \cdot 50$ \\
4 \\
$3 \cdot 78$ \\
$16 \cdot 70$ \\
$17 \cdot 1$ \\
$0 \cdot 07$ \\
$25 \cdot 06$ \\
-0.03 \\
$0 \cdot 076$ \\
$0 \cdot 0127$ \\
$7 \cdot 82$ \\
$7 \cdot 74$ \\
$21 \cdot 22$ \\
$99 \cdot 80$ \\
$78 \cdot 58$ \\
$0 \cdot 2081$
\end{tabular} & \begin{tabular}{|c}
$60 \cdot 63$ \\
$17 \cdot 51$ \\
$755 \cdot 60$ \\
$17 \cdot 2$ \\
$75 \cdot 48$ \\
$4 \frac{1}{3}$ \\
$4 \cdot 04$ \\
$17 \cdot 0$ \\
$16 \cdot 62$ \\
$0 \cdot 079$ \\
$25 \cdot 80$ \\
$-0 \cdot 04$ \\
$0 \cdot 085$ \\
$0 \cdot 014$ \\
$9 \cdot 0$ \\
$8 \cdot 89$ \\
$21 \cdot 40$ \\
$99 \cdot 80$ \\
$78 \cdot 40$ \\
$0 \cdot 2101$
\end{tabular} & \begin{tabular}{|c|}
$60 \cdot 63$ \\
$14 \cdot 17$ \\
$755 \cdot 7$ \\
$17 \cdot 4$ \\
$82 \cdot 82$ \\
$3 \frac{1}{2}$ \\
$4 \cdot 22$ \\
$17 \cdot 4$ \\
$16 \cdot 3$ \\
$0 \cdot 075$ \\
$24 \cdot 25$ \\
$-0 \cdot 024$ \\
$0 \cdot 0616$ \\
$0 \cdot 0125$ \\
$7 \cdot 72$ \\
$7 \cdot 64$ \\
$20 \cdot 46$ \\
$99 \cdot 80$ \\
$79 \cdot 34$ \\
$0 \cdot 2095$
\end{tabular} & \begin{tabular}{|c|}
$60 \cdot 70$ \\
$13 \cdot 72$ \\
$755 \cdot 72$ \\
$18 \cdot 3$ \\
$56 \cdot 83$ \\
4 \\
$3 \cdot 43$ \\
$17 \cdot 8$ \\
$17 \cdot 3$ \\
$0 \cdot 073$ \\
$24 \cdot 46$ \\
$-0 \cdot 013$ \\
$0 \cdot 0669$ \\
$0 \cdot 0120$ \\
$6 \cdot 97$ \\
$6 \cdot 86$ \\
$21 \cdot 00$ \\
$99 \cdot 80$ \\
$78 \cdot 80$ \\
$0 \cdot 2113$
\end{tabular} & \begin{tabular}{|c}
$60 \cdot 85$ \\
$16 \cdot 12$ \\
$746 \cdot 9$ \\
$20 \cdot 5$ \\
$77 \cdot 5$ \\
4 \\
$4 \cdot 03$ \\
$20 \cdot 45$ \\
$20 \cdot 52$ \\
0043 \\
$27 \cdot 95$ \\
$-0 \cdot 06$ \\
$0 \cdot 044$ \\
$0 \cdot 0139$ \\
$7 \cdot 49$ \\
$7 \cdot 53$ \\
$24 \cdot 37$ \\
$98 \cdot 60$ \\
$74 \cdot 23$ \\
$0 \cdot 2086$
\end{tabular} & \begin{tabular}{|c|c|c|}
$59 \cdot 82$ \\
$16 \cdot 83$ \\
$746 \cdot 9$ \\
$21 \cdot 2$ \\
$78 \cdot 74$ \\
4 \\
$4 \cdot 16$ \\
$4 \cdot 20$ \\
$18 \cdot 42$ \\
$0 \cdot 075$ \\
$26 \cdot 93$ \\
$-0 \cdot 023$ \\
$0 \cdot 0429$ \\
$0 \cdot 01.15$ \\
$8 \cdot 35$ \\
$8 \cdot 35$ \\
$22 \cdot 82$ \\
$100 \cdot 25$ \\
$77 \cdot 43$ \\
$0 \cdot 2091$
\end{tabular} & \begin{tabular}{|c|}
$59 \cdot 74$ \\
$16 \cdot 10$ \\
$745 \cdot 3$ \\
$22 \cdot 2$ \\
$61 \cdot 61$ \\
$4 \frac{1}{2}$ \\
$3 \cdot 58$ \\
$21 \cdot 9$ \\
$17 \cdot 51$ \\
$0 \cdot 011$ \\
26 \\
$0 \cdot 00$ \\
$0 \cdot 0563$ \\
0.013 \\
$8 \cdot 10$ \\
$7 \cdot 86$ \\
$21 \cdot 95$ \\
$101 \cdot 25$ \\
$79 \cdot 3$ \\
$0 \cdot 2061$
\end{tabular} & \begin{tabular}{|c}
$60 \cdot 04$ \\
$17 \cdot 27$ \\
$745 \cdot 36$ \\
$20 \cdot 5$ \\
$69 \cdot 36$ \\
$4 \frac{1}{2}$ \\
$3 \cdot 84$ \\
$22 \cdot 8$ \\
$21 \cdot 7$ \\
$0 \cdot 067$ \\
$29 \cdot 62$ \\
$-0 \cdot 04$ \\
$0 \cdot 0521$ \\
0.0135 \\
$7 \cdot 84$ \\
$7 \cdot 79$ \\
$25 \cdot 8$ \\
$97 \cdot 5$ \\
$71 \cdot 7$ \\
0.2082
\end{tabular} \\
\hline
\end{tabular}

The mean value is $0 \cdot 2088$; the greatest deviation from this is 0.0027. Experiments 1-5 were carried out about a month before experiments $6-9$. In the first experiments the heatingvessel was filled with boiling water, in the latter with melted paraffin. 
M. E. Wiedemann on the Specific Heats of Gases.

TABLE II.-Experiments between $150^{\circ}$ and $25^{\circ}$.

\begin{tabular}{|c|c|c|c|c|c|}
\hline & 1. & 2. & 3. & 4. & 5. \\
\hline & $60 \cdot 45$ & $60 \cdot 65$ & $60 \cdot 37$ & $60 \cdot 35$ & $60 \cdot 8$ \\
\hline & 16.40 & $12 \cdot 43$ & $12 \cdot 54$ & 12.58 & 13.5 \\
\hline В ....... & $747 \cdot 6$ & $747 \cdot 1$ & $747 \cdot 1$ & $745 \cdot 2$ & $745 \cdot 2$ \\
\hline$p \quad \ldots . .$. & 67.73 & 64.87 & 65.7 & 53.0 & 57.5 \\
\hline$\chi \quad \ldots \ldots$. & 196 & $20 \cdot 4$ & 20.9 & $19 \cdot 4$ & $20 \cdot 6$ \\
\hline$n$ & $4 \frac{1}{2}$ & $3 \frac{1}{2}$ & $3 \frac{1}{2}$ & $4 t$ & 4 \\
\hline$a \quad \ldots .$. & 3.64 & 3.55 & $3 \cdot 58$ & $3 \cdot 025$ & $\mathbf{3} \cdot \mathbf{3 8}$ \\
\hline & $19 \cdot 6$ & $20) \cdot 6$ & $21 \cdot 5$ & $19 \cdot 3$ & $20 \cdot 35$ \\
\hline $\mathbf{T} \ldots$ & $19 \cdot 55$ & $20 \cdot 85$ & $21 \cdot 82$ & $19 \cdot 36$ & $19 \cdot 35$ \\
\hline$m .$. & $0 \cdot 114$ & 0.11 & $0 \cdot 116$ & 0.103 & $0 \cdot 1$ \\
\hline $\mathbf{T}_{1} \ldots$ & $33 \cdot 20$ & $31 \cdot 55$ & $32 \cdot 05$ & 29.9 & 29.94 \\
\hline$m_{1} \ldots$ & -0.046 & -0.0125 & -0.035 & -0.02 & -0.017 \\
\hline & 0.114 & 0.1113 & $0 \cdot 121$ & $0 \cdot 1036$ & 0.089 \\
\hline$\propto .$. & 0.0117 & 0.0114 & 0.0148 & 0.0116 & 0.0109 \\
\hline$\theta \ldots$ & 13.43 & $10 \cdot 42$ & $10 \cdot 08$ & $10 \cdot 28$ & $10 \cdot 4$ \\
\hline & $13 \cdot \mathbf{3}$ & $10 \cdot 26$ & 9.94 & $10 \cdot 12$ & $10 \cdot 24$ \\
\hline & $26 \cdot 7$ & $26 \cdot 4$ & $27 \cdot 10$ & 24.86 & $24 \cdot 8$ \\
\hline $\mathbf{M} \ldots$ & $151 \cdot 5$ & $155 \cdot 1$ & $150 \cdot 7$ & $151 \cdot 7$ & $146 \cdot 0$ \\
\hline$\theta \quad \ldots .$. & $124 \cdot 8$ & 188.7 & $123 \cdot 6$ & $126 \cdot 8$ & $121 \cdot 15$ \\
\hline & $0 \cdot 2160$ & 0.2170 & \begin{tabular}{|l|l|}
0.2143 \\
\end{tabular} & 0.2147 & 0.2138 \\
\hline
\end{tabular}

he mean value is 0.2152 , and the greatest deviation therea 0.0019 .

Table III.-Experiments between $200^{\circ}$ and $25^{\circ}$.

\begin{tabular}{|c|c|c|c|c|c|c|}
\hline & 1. & 2. & 3. & 4. & 5. & 6. \\
\hline & $60 \cdot 4$ & $60 \cdot 52$ & $60 \cdot 7$ & $60 \cdot 3$ & $60 \cdot 7$ & $59 \cdot 75$ \\
\hline G... & $8 \cdot 36$ & $9 \cdot 11$ & $10 \cdot 01$ & $8 \cdot 4$ & $10 \cdot 05$ & $10 \cdot 12$ \\
\hline B ...... & $745 \cdot 2$ & $744 \cdot 63$ & $744 \cdot 65$ & $744 \cdot 65$ & 749.0 & 749.00 \\
\hline$p \quad \ldots$. & $46 \cdot 1$ & $47 \cdot 3$ & $61 \cdot 2$ & 65.3 & 62.83 & $61 \cdot 20$ \\
\hline $\begin{array}{lll}x & \ldots\end{array}$ & $21 \cdot 8$ & $22 \cdot 8$ & $23 \cdot 4$ & $23 \cdot 1$ & $20 \cdot 00$ & $20 \cdot 1$ \\
\hline $\begin{array}{ll}n & \ldots .\end{array}$ & 3 & $3_{6}$ & $3 \frac{1}{6}$ & $2 \frac{1}{2}$ & 3 & $3 \frac{1}{6}$ \\
\hline & $2 \cdot 786$ & $2 \cdot 88$ & $3 \cdot 16$ & $3 \cdot 36$ & $3 \cdot 35$ & $3 \cdot 20$ \\
\hline$\tau$ & 22 & $23 \cdot 25$ & $23 \cdot 7$ & 23.8 & $20 \cdot 2$ & 20.7 \\
\hline & 21.72 & $21 \cdot 67$ & $18 \cdot 6$ & $21 \cdot 8$ & $19 \cdot 1$ & $19 \cdot 76$ \\
\hline$m$ & $0 \cdot 14$ & 0.145 & 0.20 & $0 \cdot 20$ & 0.170 & 0.151 \\
\hline$T_{1}$. & $31 \cdot 99$ & $32 \cdot 55$ & $31 \cdot 16$ & $32 \cdot 45$ & $31 \cdot 30$ & $31 \cdot 93$ \\
\hline$m_{1}^{1}$ & 0.038 & $0 \cdot 039$ & 0.06 & 0.05 & 0.04 & 0.007 \\
\hline$k$. & $0 \cdot 137$ & 0.129 & 0.1435 & $0 \cdot 172$ & $0 \cdot 158$ & $0 \cdot 133$ \\
\hline & 0.01 & 0.097 & $0 \cdot 0112$ & 0.0141 & 0.0107 & 0.0118 \\
\hline$\theta$ & $9 \cdot 74$ & $10 \cdot 24$ & $11 \cdot 72$ & $9 \cdot 84$ & 11.53 & $11 \cdot 70$ \\
\hline$\theta_{1}$ & $9 \cdot 485$ & $9 \cdot 9$ & 11.31 & $\mathbf{9} \cdot \mathbf{5 3}$ & $11 \cdot 22$ & 11.48 \\
\hline$t$. & 27 & $27 \cdot 2$ & 25.05 & $\mathbf{2 7 \cdot 3}$ & $25 \cdot 35$ & $26 \cdot 04$ \\
\hline M. & $202 \cdot 1$ & $200 \cdot 45$ & $201 \cdot 1$ & $202 \cdot 8$ & 196.35 & $196 \cdot 25$ \\
\hline$\theta \ldots$ & $175 \cdot 1$ & $173 \cdot 25$ & 176.05 & $175 \cdot 5$ & 171 & $170 \cdot 20$ \\
\hline$c \quad \ldots .$. & 0.2230 & 0.2182 & 0.2193 & 0.2181 & 0.2188 & 0.2207 \\
\hline
\end{tabular}

The number 0.2197 represents the mean value, and 0.0033 the greatest deviation from the mean.

Phil. Mag. S. 5. Vol. 2. No. 9. Aug. 1876. 
My numbers agree among themselves as well as those obtained by Régnault; for instance, he obtained values for the specific heat between $210^{\circ}$ and $10^{\circ}$ varying from $0 \cdot 21416$ to $0 \cdot 21844$ \&c. It appears, alike from Régnault's and from my experiments, that there is a great change in the specific heat of the gas under examination with change of temperature.

The true specific heats calculated from the foregoing numbers for certain temperatures are as follows :-

$$
\begin{aligned}
& \text { For } \stackrel{\circ}{0} \text {. . . . . } 0.1952 \\
& 100 \text {. . . . } 0.2169 \\
& 200 . . .0 .2387
\end{aligned}
$$

Régnault's numbers are :-

$$
\text { For } \begin{array}{rllllll}
0 & . & . & . & . & . & 0 \cdot 1870 \\
100 & . & . & . & . & . & 0 \cdot 2145 \\
200 & . & . & . & . & . & 0 \cdot 2397
\end{array}
$$

Taking the specific gravity of carbonic acid as 1.529 , the following numbers express the relative heats :-

$$
\text { For } \begin{array}{rllllll}
0 & . & . & . & . & . & 0.2985 \\
100 & . & . & . & . & . & 0.3316 \\
200 & . & . & . & . & . & 0.3650
\end{array}
$$

\section{Carbonic Oxide.}

The gas was prepared by Fowne's method, viz. heating one part of yellow prussiate of potash with eight parts of concentrated sulphuric acid. The gas was led through caustic potash and then through sulphuric acid : it was entirely absorbed by a solution of cuprous chloride in hydrochloric acid; it contained no carbonic acid. Oxalic acid was not used for the preparation of the gas, inasmuch as the carbonic acid simultaneously produced can only be separated with great difficulty.

The numbers given in the two following Tables yield almost exactly the same values for the specific heat; so that we may conclude that the specific heat of carbonic oxide is independent of the temperature. Régnault's number between $200^{\circ}$ and $20^{\circ}$, viz. $0 \cdot 2450$, does not differ materially from mine.

The relative heat of carbonic oxide is 0.2346 (the specific gravity being taken as 0.967 ), which is nearly the same as that of air $-0 \cdot 2389$. 
TABLE I.-Experiments between $100^{\circ}$ and $25^{\circ}$.

\begin{tabular}{|c|c|c|c|c|c|}
\hline & J. & 2. & 3. & 4. & 5. \\
\hline & $60 \cdot 36$ & $60 \cdot 85$ & 61.03 & $60 \cdot 65$ & $60 \cdot 13$ \\
\hline & 18.38 & $16 \cdot 45$ & $18 \cdot 31$ & 18.81 & $18 \cdot 47$ \\
\hline В $\ldots \ldots$ & $745 \cdot 6$ & $745 \cdot 6$ & $750 \cdot 5$ & $750 \cdot 3$ & $753 \cdot 3$ \\
\hline $\begin{array}{ll}p & \ldots\end{array}$ & $\mathbf{7 5} \cdot \mathbf{5}$ & $73 \cdot 7$ & $77 \cdot 9$ & $77 \cdot 1$ & $80 \cdot 8$ \\
\hline$x \ldots$ & $22 \cdot 8$ & $23 \cdot 1$ & $19 \cdot 9$ & $20 \cdot 4$ & 20.2 \\
\hline $\begin{array}{ll}n & \ldots \ldots .\end{array}$ & $4 \frac{1}{2}$ & 4 & $4 \frac{1}{2}$ & $4 \frac{1}{2}$ & $4 \frac{1}{2}$ \\
\hline$a \quad \ldots$ & 4.084 & $4 \cdot 11$ & 4.07 & $4 \cdot 18$ & $4 \cdot 105$ \\
\hline$\tau \quad \ldots \ldots$ & $22 \cdot 6$ & 23 & $20 \cdot 105$ & $20 \cdot 3$ & $19 \cdot 95$ \\
\hline $\mathbf{T} \ldots$ & $21 \cdot 05$ & 18.55 & $18 \cdot 07$ & $18 \cdot 03$ & $20 \cdot 48$ \\
\hline$m \ldots$ & 0.0625 & 0.1104 & 0.079 & 0.083 & 0.073 \\
\hline$T_{1} \ldots \ldots$ & $27 \cdot 65$ & $24 \cdot 93$ & $25 \cdot 09$ & $25 \cdot 19$ & $27 \cdot 68$ \\
\hline$m_{1} \ldots \ldots$ & -0.017 & 0.027 & -0.004 & $0 \cdot 0033$ & -0.013 \\
\hline$k^{*} \ldots \ldots$ & 0.0442 & 0.050 & 0.0557 & 0.057 & 0.079 \\
\hline * $\ldots .$. & 0.0120 & 0.0119 & 0.0117 & 0.0112 & 0.0103 \\
\hline$\theta \quad \ldots .$. & 640 & $5 \cdot 98$ & 6.73 & 6.88 & $7 \cdot 00$ \\
\hline$\theta_{1}, \ldots \ldots$ & $6 \cdot 3$ & $5 \cdot 72$ & 6.57 & $6 \cdot 69$ & 6.84 \\
\hline$t$. & $21 \cdot 5$ & $21 \cdot 8$ & $21 \cdot 71$ & $21 \cdot 74$ & $\mathbf{2 4 \cdot 2 0}$ \\
\hline M. & 98 & $97 \cdot 6$ & $98 \cdot 6$ & 98 & 103 \\
\hline$\theta$. & $73 \cdot 5$ & $75 \cdot 8$ & 76.9 & $76 \cdot 26$ & $78 \cdot 8$ \\
\hline$c \quad \ldots .$. & 0.2450 & $0 \cdot 2420$ & 0.2432 & $\mathbf{0 \cdot 2 4 2 5}$ & $0 \cdot 2399$ \\
\hline
\end{tabular}

Mean value $=0.2425$; greatest deviation $=0.0026$.

TABLE II.-Experiments between $200^{\circ}$ and $25^{\circ}$.

\begin{tabular}{|c|c|c|c|c|c|}
\hline & 1. & 2. & 3. & 4. & 5. \\
\hline W.. & 60.95 & $59 \cdot 8$ & 60 & 59.9 & $60 \cdot 65$ \\
\hline G...... & $11 \cdot 27$ & $11 \cdot 70$ & $12 \cdot 71$ & 11.5 & $12 \cdot 61$ \\
\hline В ...... & $750 \cdot 15$ & $750 \cdot 15$ & $750 \cdot 15$ & 753.3 & $753 \cdot 3$ \\
\hline$p \quad \ldots .$. & $44 \cdot 9$ & $58 \cdot 34$ & $57 \cdot 52$ & $45 \cdot 3$ & $65 \cdot 2$ \\
\hline$\chi \ldots \ldots$ & $21 \cdot 6$ & $21 \cdot 4$ & $21 \cdot 6$ & $20 \cdot 4$ & $20 \cdot 4$ \\
\hline$n \quad \ldots .$. & 4 & $3 \frac{1}{2}$ & 4 & $4 \frac{1}{2}$ & 4 \\
\hline$a$ & $2 \cdot 82$ & $3 \cdot 34$ & $3 \cdot 18$ & $2 \cdot 55$ & $3 \cdot 15$ \\
\hline$\tau \ldots$ & $2 \overline{2} \cdot 2$ & $21 \cdot 7$ & $21 \cdot 55$ & $20 \cdot 65$ & 20 \\
\hline T ... & $22 \cdot 6$ & $17 \cdot 63$ & $21 \cdot 54$ & $21 \cdot 15$ & 21 \\
\hline$m \ldots . .$. & $0 \cdot 2$ & $0 \cdot 234$ & $0 \cdot 184$ & 0.18 & $0 \cdot 17$ \\
\hline$T_{1} \ldots .$. & $32 \cdot 9$ & $28 \cdot 45$ & $32 \cdot 9$ & $31 \cdot 35$ & $32 \cdot 23$ \\
\hline$m_{1} \ldots \ldots$ & 0.07 & $0 \cdot 05$ & 0.01 & 0.0571 & 0.033 \\
\hline$k \ldots$ & $0 \cdot 205$ & $0 \cdot 166$ & $0 \cdot 184$ & 0.182 & $0 \cdot 182$ \\
\hline $\boldsymbol{\alpha} \quad \ldots$ & 0.0126 & 0.017 & 0.0127 & 0.0121 & 0.0122 \\
\hline & $9 \cdot 92$ & $9 \cdot 63$ & $10 \cdot 48$ & $9 \cdot 33$ & $10 \cdot 43$ \\
\hline$\theta_{1}$. & 8.70 & $9 \cdot 15$ & 10.08 & $8 \cdot 83$ & $10 \cdot 03$ \\
\hline & 28 & $23 \cdot 38$ & $27 \cdot 43$ & $26 \cdot 44$ & 26.8 \\
\hline & $202 \cdot 75$ & $194 \cdot 75$ & $199 \cdot 1$ & 194.9 & $198 \cdot 45$ \\
\hline$\theta \ldots .$. & $174 \cdot 75$ & $171 \cdot 38$ & $171 \cdot 67$ & 168.46 & $171 \cdot 65$ \\
\hline & $0 \cdot 2407$ & $0 \cdot 2407$ & 0.2442 & 0.2444 & 0.2431 \\
\hline
\end{tabular}

Mean value $=0.2426$; greatest deviation $=0.0019$. 


\section{Ethylene.}

The ethylene was produced by Mitscherlich's method, viz. by leading alcohol vapour into tolerably concentrated sulphuric acid heated to $160^{\circ}$ or $170^{\circ}$. The gas was cooled to condense ether, which is always produced along with the ethylene, and then passed through caustic potash and through concentrated sulphuric acid into a gasometer. The last traces of ether were given up to the water in the gasometer; and the gas, after being dried by means of sulphuric acid, could be passed into the caoutchouc balloon.

Inasmuch as by-products are always formed in the production of ethylene, so great an agreement among the results of experiments cannot be expected in the case of this as of the other gases.

TABLE I.-Experiments between $100^{\circ}$ and $25^{\circ}$.

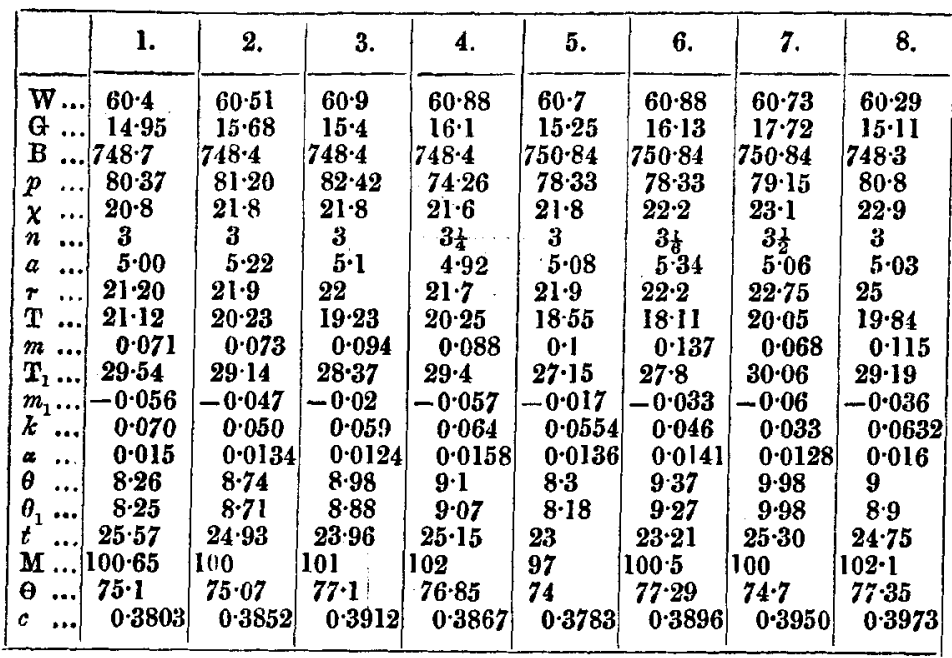

Mean value $=0.3880 ;$ greatest deviation $=0.0093$. 
M. E. Wiedemann on the Specific Heats of Gases. 101

TABLE II. - Experiments between $200^{\circ}$ and $27^{\circ}$.

\begin{tabular}{|c|c|c|c|c|c|c|}
\hline & 1. & 2. & 3. & 4. & 5. & 6. \\
\hline & $60 \cdot 81$ & $59 \cdot 85$ & $60 \cdot 65$ & 60.43 & $60 \cdot 75$ & 60.9 \\
\hline & 7.93 & $7 \cdot 55$ & $7 \cdot 24$ & 5.98 & 8.06 & $7 \cdot 22$ \\
\hline & 752.88 & $752 \cdot 88$ & $752 \cdot 88$ & $752 \cdot 88$ & $748 \cdot 3$ & $748 \cdot 3$ \\
\hline$p \quad .$. & 57.52 & 46.92 & $46 \cdot 5$ & $45 \cdot 7$ & 47 & $48 \cdot 1$ \\
\hline$x$. & $20 \cdot 4$ & $20 \cdot 8$ & $21 \cdot 2$ & $21 \cdot 6$ & 21.8 & $22 \cdot 4$ \\
\hline $\begin{array}{ll}n & \ldots\end{array}$ & $2 \frac{1}{3}$ & $2 \frac{1}{g}$ & 2 & 13 & $2_{\frac{1}{d}}$ & \\
\hline$a \ldots$ & $3 \cdot 40$ & $3 \cdot 3$ & $3 \cdot 62$ & $3 \cdot 42$ & 372 & 3.61 \\
\hline & $20 \cdot 75$ & $20 \cdot 55$ & $21 \cdot 35$ & $21 \cdot 85$ & 22 & $22 \cdot 6$ \\
\hline & $20 \cdot 86$ & $19 \cdot 7$ & $21 \cdot 05$ & $23 \cdot 15$ & $21 \cdot 25$ & $21 \cdot 36$ \\
\hline$m$ & $0 \cdot 184$ & $0 \cdot 17$ & $0 \cdot 164$ & 0.17 & 0.14 & $0 \cdot 133$ \\
\hline & $32 \cdot 60$ & $30 \cdot 67$ & $32 \cdot 10$ & $32 \cdot 77$ & $32 \cdot 53$ & $31 \cdot 96$ \\
\hline & 0.014 & 0.028 & $0 \cdot 0166$ & 0.006 & $-0 \cdot 005$ & -0.0025 \\
\hline & 0.172 & $0 \cdot 159$ & 0.158 & $0 \cdot 192$ & $0 \cdot 130$ & 0.118 \\
\hline$\infty$. & 0.0134 & 0.013 & $0 \cdot 0133$ & 0.017 & 0.0129 & 0.0128 \\
\hline$\theta$ & $10 \cdot 83$ & $10 \cdot 22$ & $10 \cdot 3$ & $8 \cdot 75$ & 10. & $10 \cdot 1$ \\
\hline$\theta_{1}$ & $10 \cdot 65$ & $10 \cdot 02$ & $10 \cdot 13$ & 861 & 10 & 9.98 \\
\hline$t^{t}$ & $27 \cdot 08$ & $25 \cdot 4$ & $26 \cdot 85$ & $28 \cdot 35$ & $27 \cdot 15$ & 26.86 \\
\hline & 197.5 & $200 \cdot 2$ & $203 \cdot 25$ & 204.75 & $195 \cdot 4$ & 200 \\
\hline$\theta$. & $170 \cdot 4$ & 174.8 & 176.4 & $176 \cdot 4$ & $168 \cdot 25$ & $173 \cdot 14$ \\
\hline & 0.4195 & 0.4267 & 0.4286 & 0.4401 & 0.4251 & 0.4361 \\
\hline
\end{tabular}

The mean value is $0 \cdot 4293$; the greatest deviation therefrom $0 \cdot 0108$.

The order of experiments was $1,2,3,4,1 a, 2 a, 3 a, 5,6$, $7,4 a, 5 a, 8,6 a$. The number 0.4293 does not differ very much from that obtained by Régnault, viz. $0 \cdot 404$ (mean of $0 \cdot 4147$ and $0 \cdot 3933$ ). Régnault did not carry out experiments between $100^{\circ}$ and $20^{\circ}$.

Ethylene, like carbonic acid and nitrous oxide, shows a considerable change in specific heat for changes of temperature. The following true specific heats are calculated :-

$$
\begin{aligned}
& \text { For } 0 \text {. . . . . } 0.3364 \\
& 100 . . . \quad 044189 \\
& 200 \text {. . . . } 0.5015
\end{aligned}
$$

Multiplying by the specific gravity of ethylene $(0.9672)$ we obtain the relative heats :-

$$
\begin{aligned}
& \text { For } 100^{\circ} \text {. . . . 0-3254 } \\
& 150 \text {. . . . } 0.405 \\
& 200 \text {. . . . } 0.4851
\end{aligned}
$$

Nitrous Oxide.

The gas was prepared by long-continued heating of ammonium nitrate free from chloride and nitrite; it was purified by passage through caustic potash (to absorb ammonium nitrate carried over and nitric acid) and through sulphuric acid (to absorb free ammonia). 
M. E. Wiedemann on the Specific Heats of Gases.

TABle I.-Experiments between $100^{\circ}$ and $25^{\circ}$.

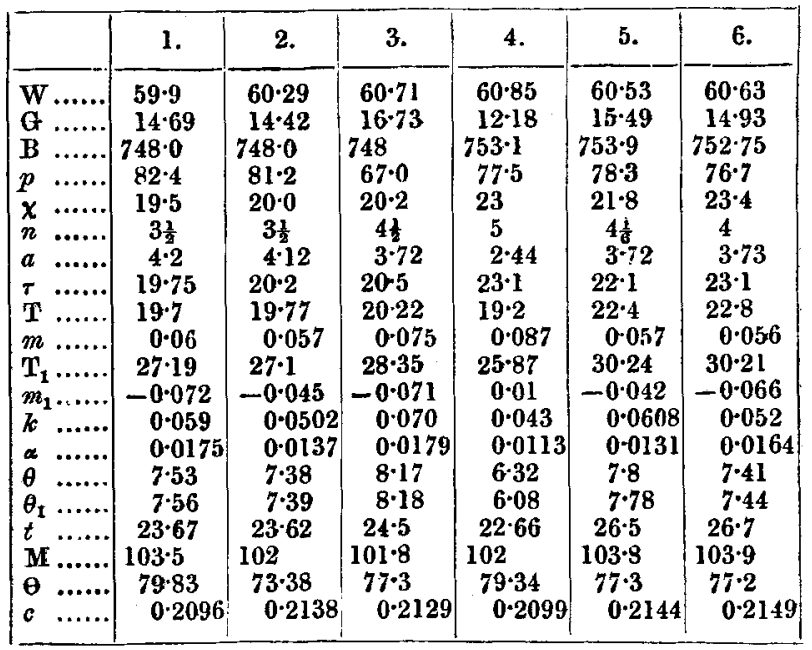

The mean value is $0 \cdot 2126$; greatest deviation $0 \cdot 0030$.

Experiments 4, 5, and 6 were carried out after those recorded in Table II.

Table II.--Experiments between $200^{\circ}$ and $25^{\circ}$.

\begin{tabular}{|c|c|c|c|c|c|}
\hline & & 1. & 2. & 3. & 4. \\
\hline $\mathbf{W}$ & & $60 \cdot 38$ & $60 \cdot 45$ & 60.5 & $59 \cdot 92$ \\
\hline$\theta$ & & $9 \cdot 01$ & $9 \cdot 18$ & $9 \cdot 87$ & 8.54 \\
\hline $\mathbf{B}$ & & $748 \cdot 61$ & $748 \cdot 61$ & $753 \cdot 3$ & $753 \cdot 3$ \\
\hline & ........... & $58 \cdot 34$ & $65 \cdot 3$ & $58 \cdot 75$ & 71.4 \\
\hline$x$ & ........... & $21 \cdot 6$ & $22 \cdot 8$ & $21 \cdot 6$ & $22 \cdot 4$ \\
\hline$n$ & & $2 \frac{3}{4}$ & $2 \frac{2}{3}$ & 3 & $2 \frac{1}{6}$ \\
\hline$a$ & & $\mathbf{3} \cdot \mathbf{2 8}$ & $3 \cdot 44$ & 3.29 & $3 \cdot 94$ \\
\hline$r$ & .......... & $22 \cdot 2$ & $23 \cdot 4$ & 22 & $22 \cdot 35$ \\
\hline $\mathbf{T}$ & & $19 \cdot 67$ & 20.85 & 20 & 22.55 \\
\hline$m$ & …................... & 0.225 & $0 \cdot 21$ & 0.2 & 0.173 \\
\hline $\mathbf{T}_{1}$ & ........... & $31 \cdot 46$ & $33 \cdot 03$ & $32 \cdot 85$ & $34 \cdot 40$ \\
\hline$m_{1}$ & $\ldots$ & 0.072 & 0.065 & 0.036 & 0.022 \\
\hline$k$ & & 0.192 & 0.180 & $0 \cdot 1748$ & $0 \cdot 166$ \\
\hline$a$ & $\ldots$ & $0 \cdot 0130$ & 0.0119 & 0.0128 & 0.0125 \\
\hline$\theta$ & & $10 \cdot 82$ & $11 \cdot 12$ & $12 \cdot 04$ & $10 \cdot 94$ \\
\hline$\theta_{1}$ & .......... & $10 \cdot 46$ & $10 \cdot 7$ & $11 \cdot 67$ & $10 \cdot 74$ \\
\hline$t^{1}$ & & $25 \cdot 75$ & $27 \cdot 24$ & $26 \cdot 6$ & $28 \cdot 84$ \\
\hline $\mathbf{M}$ & $\ldots$ & 201 & $201 \cdot 45$ & $210 \cdot 1$ & $212 \cdot 1$ \\
\hline$\theta$ & .... & $175 \cdot 24$ & $174 \cdot 21$ & $183 \cdot 5$ & $183 \cdot 26$ \\
\hline$c$ & .......... & $0 \cdot 2248$ & 0.2262 & 0.2187 & 0.2267 \\
\hline
\end{tabular}

The mean value is 0.2241 ; greatest deviation 0.0054 . 
The specific heat found between $200^{\circ}$ and $25^{\circ}$ is almost identical with the number $0 \cdot 22616$ obtained by Régnault. From Régnault's experiments carried out for the temperatureinterval $165^{\circ}$ to $200^{\circ}$, as well as from my own results, it appears that the specific heat of nitrous oxide increases with increase of temperature.

From the foregoing measurements the following true specific heats are deduced :-

$$
\text { For } \begin{array}{rllllll}
0 & . & . & . & . & . & 0 \cdot 1083 \\
100 & . & . & . & . & . & 0 \cdot 2212 \\
200 & . & . & . & . & . & 0 \cdot 2442
\end{array}
$$

Multiplying these numbers by the specific gravity of nitrous oxide $(1.52)$ we obtain the relative heats :-

$$
\text { For } \begin{array}{rllllll}
0 & . & . & . & . & . & 0 \cdot 3014 \\
100 & . & . & . & . & . & 0.3362 \\
200 & . & . & . & . & . & 0.3712
\end{array}
$$

Ammonia.

The gas was prepared by gently warming the strongest ammonia of commerce, and dried by passage through a long tube filled with lime.

In order to regulate the velocity of the flow, the gas was passed through a small flask containing mercury and then through an empty flask.

\begin{tabular}{|c|c|c|c|c|c|c|}
\hline & 1. & 2. & 3. & 4. & 5. & 6. \\
\hline W... & $60 \cdot 38$ & $61 \cdot 45$ & $60 \cdot 33$ & $59 \cdot 77$ & $60 \cdot 9$ & $60 \cdot 62$ \\
\hline G... & $16 \cdot 12$ & $13 \cdot 97$ & $13 \cdot 38$ & $15 \cdot 12$ & $14 \cdot 78$ & $16 \cdot 41$ \\
\hline В ............. & $753 \cdot 3$ & $752 \cdot 46$ & $749 \cdot 62$ & $747 \cdot 62$ & $749 \cdot 68$ & $747 \cdot 4$ \\
\hline$p \quad \ldots \ldots \ldots$ & $60 \cdot 0$ & 69.04 & $70 \cdot 59$ & $73 \cdot 04$ & 60.32 & $61 \cdot 2$ \\
\hline$x \ldots \ldots$. & $19 \cdot 8$ & $16 \cdot 3$ & $17 \cdot 2$ & $17 \cdot 00$ & 17 & 25 \\
\hline$n \quad \ldots \ldots$. & 4 & 3 & 3 & $3 \frac{1}{3}$ & $3 \frac{1}{2}$ & 4 \\
\hline$a \ldots$ & 4.03 & $4 \cdot 66$ & $4 \cdot 46$ & $4 \cdot 54$ & $4 \cdot 22$ & $4 \cdot 10$ \\
\hline$\tau \ldots$ & 19.9 & 16.0 & $15 \cdot 9$ & 16.85 & $16 \cdot 75$ & $25 \cdot 15$ \\
\hline $\mathrm{T} .$. & $17 \cdot 9$ & $16 \cdot 38$ & $15 \cdot 9$ & $16 \cdot 4$ & $15 \cdot 8$ & $22 \cdot 65$ \\
\hline$m .$. & 0.08 & 0.078 & 0.086 & $0 \cdot 101$ & 0.098 & 0.098 \\
\hline $\mathbf{T}_{1} \ldots \ldots \ldots$ & $25 \cdot 8$ & $23-45$ & 23.03 & $24 \cdot 39$ & $23 \cdot 24$ & $30 \cdot 50$ \\
\hline$m_{1} \ldots \ldots \ldots$ & -0.033 & -0.05 & 0.00 & -0.0075 & 0.0025 & -0.013 \\
\hline$k^{1} .$. & 0.0513 & 0.0848 & 0.086 & 0.095 & 0.087 & 0.063 \\
\hline *.. & 0.0143 & 0.0180 & 0.012 & 0.0136 & 0.0130 & 0.014 \\
\hline$\theta \quad \ldots$ & $7 \cdot 76$ & 6.79 & 6.83 & $7 \cdot 69$ & $7 \cdot 24$ & $7 \cdot 44$ \\
\hline$\theta_{1} \ldots$ & $7 \cdot 68$ & $6 \cdot 76$ & 6.7 & $7 \cdot 54$ & $7 \cdot 06$ & $7 \cdot 28$ \\
\hline & $22 \cdot 9$ & $20 \cdot 0$ & $19 \cdot 6$ & $20 \cdot 55$ & $19 \cdot 6$ & $26 \cdot 82$ \\
\hline M... & 99.8 & $99 \cdot 7$ & $99 \cdot 6$ & $99 \cdot 6$ & $99 \cdot 6$ & 102.0 \\
\hline$\theta \quad \ldots \ldots \ldots$ & $77 \cdot 8$ & $79 \cdot 5$ & 80 & $79 \cdot 05$ & 80 & $75 \cdot 2$ \\
\hline c $\quad \ldots . . . . . .$. & 0.5226 & & 0.5246 & 0.5226 & 0.5108 & 0.5173 \\
\hline
\end{tabular}

The manometer $(k)$ contained concentrated ammonia instead of water during the following experiments. A three-way stopcock served to lead away the excess of gas after leaving the balloon.

TABLE I.-Experiments between $100^{\circ}$ and $25^{\circ}$. 
Table I. (continued).

\begin{tabular}{|c|c|c|c|c|c|c|}
\hline & 7. & 8. & 9. & 10. & 11. & 12. \\
\hline & $59 \cdot 49$ & $60 \cdot 23$ & $60 \cdot 64$ & 60 & 60.96 & 66.83 \\
\hline & $16 \cdot 65$ & 16.75 & 14.35 & $14 \cdot 76$ & $15 \cdot 72$ & $17 \cdot 7$ \\
\hline B .. & $747 \cdot 40$ & $746 \cdot 6$ & $746 \cdot 6$ & $747 \cdot 3$ & $747 \cdot 3$ & $747 \cdot 3$ \\
\hline$p .$. & $63 \cdot 24$ & $64 \cdot 1$ & $71 \cdot 0$ & $69 \cdot 0$ & 69.8 & 71 \\
\hline$x$. & $25 \cdot 2$ & 24 & $24 \cdot 2$ & $23 \cdot 3$ & $23 \cdot 7$ & $24 \cdot 0$ \\
\hline$n$ & 4 & 4 & 4 & 4 & $4 \frac{1}{8}$ & $4 \frac{8}{4}$ \\
\hline$a$. & $4 \cdot 16$ & $4 \cdot 19$ & $3 \cdot 59$ & $3 \cdot 69$ & $3 \cdot 77$ & $3 \cdot 73$ \\
\hline & $25 \cdot 3$ & 23.7 & $24 \cdot 2$ & $23 \cdot 1$ & $23 \cdot 6$ & $24 \cdot 1$ \\
\hline T. & $21 \cdot 68$ & $22 \cdot 25$ & 22.56 & 21 & $20 \cdot 56$ & $21 \cdot 11$ \\
\hline & 0.137 & 0.078 & 0.09 & 0.1 & $0 \cdot 123$ & $0 \cdot 126$ \\
\hline & $29 \cdot 7$ & $30 \cdot 05$ & $29 \cdot 60$ & $28 \cdot 78$ & $28 \cdot 95$ & $29 \cdot 85$ \\
\hline$m_{1} \ldots \ldots \ldots$ & 0.002 & -0.025 & 0.0025 & $0 \times 0066$ & 0.08 & 0.017 \\
\hline & 0.0785 & 0.059 & 0.071 & 0.076 & 0.085 & 0.089 \\
\hline & 0.0175 & 0.0131 & 0.0128 & 0.0125 & 0.0125 & 0.0124 \\
\hline & $7 \cdot 49$ & $7 \cdot 6$ & $6 \cdot 68$ & 7.35 & 7.77 & $8 \cdot 37$ \\
\hline & $7 \cdot 24$ & $7 \cdot 5$ & 6.5 & $7 \cdot 14$ & $7 \cdot 49$ & 8.04 \\
\hline & $26 \cdot 0$ & 26.4 & $26 \cdot 26$ & $25 \cdot 1$ & $25 \cdot 0$ & $25 \cdot 6$ \\
\hline & $99 \cdot 5$ & $101 \cdot 8$ & $100 \cdot 96$ & 104 & 103.5 & $100 \cdot 6$ \\
\hline$\theta \ldots$ & $73 \cdot 5$ & $75 \cdot 4$ & $74 \cdot 7$ & $78 \cdot 9$ & $78 \cdot 5$ & 75 \\
\hline & 0.5084 & 0.5201 & 0.5246 & 0.5245 & 0.5271 & 0.5240 \\
\hline
\end{tabular}

The mean value is 0.5202 ; greatest deviation 0.0118 . In experiments 1 to 6 the heating-vessel contained boiling water.

TABLE II.-Experiments between $200^{\circ}$ and $25^{\circ}$.

\begin{tabular}{|c|c|c|c|c|c|c|}
\hline & 1. & 2. & 3. & 4. & 5. & 6. \\
\hline W.......... & $60 \cdot 84$ & 60.71 & $60 \cdot 3$ & $60 \cdot 49$ & $61 \cdot 04$ & $60 \cdot 21$ \\
\hline G $\ldots \ldots \ldots$ & $6 \cdot 2$ & $7 \cdot 6$ & $9 \cdot 59$ & $8 \cdot 2$ & $7 \cdot 34$ & $9 \cdot 54$ \\
\hline B ............. & $750 \cdot 6$ & $750 \cdot 6$ & $750 \cdot 6$ & $750 \cdot 3$ & $750 \cdot 3$ & $750 \cdot 3$ \\
\hline$p$ & $45 \cdot 3$ & $45 \cdot 3$ & $47 \cdot 7$ & $\mathbf{3 7} \cdot \mathbf{1}$ & $33 \cdot 0$ & 46.51 \\
\hline$x \ldots \ldots$ & 23 & 23 & $23 \cdot 6$ & $23 \cdot 8$ & $23 \cdot 8$ & $24 \cdot 1$ \\
\hline$n \ldots \ldots \ldots$ & 2 & $2 \frac{1}{2}$ & 3 & 3 & 3 & 3 \\
\hline$a \quad \ldots \ldots . . .$. & $3 \cdot 1$ & 3.04 & $3 \cdot 2$ & $2 \cdot 73$ & $2 \cdot 44$ & $3 \cdot 18$ \\
\hline t $\ldots \ldots . . .$. & $23 \cdot 06$ & $23 \cdot 2$ & 23.9 & $23 \cdot 8$ & $23 \cdot 8$ & $24 \cdot 15$ \\
\hline $\mathbf{T} .$. & $23 \cdot 25$ & $22 \cdot 68$ & $19 \cdot 78$ & $20 \cdot 76$ & $21 \cdot 5$ & $20 \cdot 75$ \\
\hline$m .$. & 0.185 & $0 \cdot 204$ & $0 \cdot 23$ & 0.183 & 0.20 & 0.22 \\
\hline$T_{1} \ldots \ldots \ldots$ & $30 \cdot 9$ & $31 \cdot 85$ & $31 \cdot 37$ & $30 \cdot 5$ & $30 \cdot 24$ & $31 \cdot 95$ \\
\hline$m_{1} \ldots \ldots \ldots$ & 0.058 & 0.06 & 0.075 & 0.06 & 0.07 & 0054 \\
\hline$k .$. & 0.183 & 0.195 & 0.175 & 0.145 & $0 \cdot 165$ & $0 \cdot 169$ \\
\hline * ... & $0 \cdot 0162$ & 0.0157 & 0.0134 & $0 \cdot 0126$ & 0.015 & 0.015 \\
\hline$\theta \quad \ldots \ldots \ldots$ & 6.83 & $8 \cdot 42$ & 10.55 & $8 \cdot 93$ & $7 \cdot 99$ & $10 \cdot 45$ \\
\hline$\theta_{1} \ldots \ldots \ldots$ & $6 \cdot 59$ & $8 \cdot 1$ & $10 \cdot 1$ & $8 \cdot 57$ & $7 \cdot 59$ & 10.05 \\
\hline & $27 \cdot 20$ & $27 \cdot 4$ & $25 \cdot 73$ & $25 \cdot 85$ & 26.0 & 26.52 \\
\hline $\mathbf{M} \ldots \ldots \ldots$ & 203.8 & 203.9 & $200 \cdot 8$ & $201 \cdot 0$ & 200.0 & 20044 \\
\hline$\theta \ldots \ldots \ldots$ & 176.6 & 176.5 & $175 \cdot 07$ & $175 \cdot 15$ & $174^{\circ} 0$ & 173.88 \\
\hline$c \quad \ldots . . . . .$. & & 0.5349 & 0.5291 & 0.5341 & \begin{tabular}{|l|}
0.5392 \\
\end{tabular} & 0.5340 \\
\hline
\end{tabular}


Table II (continued).

\begin{tabular}{|c|c|c|c|c|c|}
\hline & 7. & 8. & 9. & 10. & 11. \\
\hline & $60 \cdot 74$ & 60.96 & $61 \cdot 01$ & $60 \cdot 18$ & $60 \cdot 91$ \\
\hline & $6 \cdot 81$ & $7 \cdot 02$ & $8 \cdot 15$ & $8 \cdot 3$ & 6.6 \\
\hline B ... & $750 \cdot 3$ & 745.8 & $745 \cdot 8$ & $7+7 \cdot 7$ & $747 \cdot 7$ \\
\hline$p \quad \ldots$ & $45 \cdot 3$ & $51 \cdot 4$ & $48 \cdot 9$ & $45 \cdot 9$ & $44 \cdot 0$ \\
\hline$x$ & $24 \cdot 4$ & $25 \cdot 6$ & $26 \cdot 0$ & $24 \cdot 8$ & $25 \cdot 0$ \\
\hline & $2 \frac{1}{6}$ & $2 \frac{1}{2}$ & 3 & $\hat{\delta}_{\frac{1}{6}}$ & $2 \frac{3}{2}$ \\
\hline$a$ & $3 \cdot 14$ & $2 \cdot 81$ & $2 \cdot 72$ & $2 \cdot 61$ & $2 \cdot 604$ \\
\hline & $24 \cdot 4$ & $26 \cdot 0$ & $26 \cdot 6$ & $24 \cdot 5$ & 25 \\
\hline T ...... & $23 \cdot 07$ & $23 \cdot 35$ & 22.5 & $21 \cdot 14$ & $21 \cdot 26$ \\
\hline$m$. & 0.26 & $0 \cdot 2$ & 0 & 0 & 55 \\
\hline$T_{1}$ & $32 \cdot 01$ & $33 \cdot 15$ & $32 \cdot 65$ & $32 \cdot 0$ & $30 \cdot 44$ \\
\hline$m_{1} \ldots$ & 0.13 & 0.135 & $0 \cdot 15$ & $0 \cdot 16$ & 0.17 \\
\hline$k \ldots$ & 0.242 & $0 \cdot 22$ & 0.242 & $0 \cdot 29$ & $0 \cdot 277$ \\
\hline$a \ldots .$. & 0.0145 & $0 \cdot 012$ & 0.0148 & 0.0174 & 0.0196 \\
\hline & $7 \cdot 64$ & $7 \cdot 95$ & $8 \cdot 9$ & $9 \cdot 22$ & $7 \cdot 13$ \\
\hline$\theta_{1} .$. & $7 \cdot 22$ & $7 \cdot 48$ & $8 \cdot 27$ & $8 \cdot 40$ & $6 \cdot 50$ \\
\hline$t$ & $27 \cdot 6$ & $28 \cdot 55$ & $27 \cdot 8$ & $26^{\circ} 6$ & $26 \cdot 22$ \\
\hline M.. & $201 \cdot 0$ & $202 \cdot 3$ & $199 \cdot 9$ & $196 \cdot 9$ & $192 \cdot 65$ \\
\hline$\theta \ldots \ldots$. & $173 \cdot 4$ & $173 \cdot 75$ & $172 \cdot 1$ & 170.3 & 166.43 \\
\hline & 0.5448 & 0.5493 & 0.5322 & 0.5270 & 0.5323 \\
\hline
\end{tabular}

The mean value is 0.5356 ; greatest deviation 0.0137 .

Régnault's number for the specific heat of ammonia between $200^{\circ}$ and $20^{\circ}$, viz. 0.50836 , is, as he himself supposed, rather too small; according to my researches it should be 0.5356 .

The true specific heats are deduced as follows :-

$$
\begin{aligned}
& \text { For } 0 \text {. . . . . } 0.5009 \\
& 100 \text {. . . . . } 0.5387 \\
& 200 \text {. . . . } 0.5629
\end{aligned}
$$

Multiplying the numbers by 0.5894 (the specific gravity of ammonia), we obtain the relative heats :-

$$
\begin{aligned}
& \text { For } 0 \text {. . . . . } 0.2952 \\
& 100 \text {. . . . } 0.3134 \\
& 200 \text {. . . } 033378
\end{aligned}
$$

The specific heat of ammonia increases therefore with increase of temperature, although not in so marked a manner as in the cases of nitrous oxide, carbonic acid, and ethylene.

\section{Conclusion.}

A comparison of the results obtained by the method described above with those obtained by Régnault, shows that my results are in no respect less exact than his. But inasmuch as the quantity of water in my calorimeter was but the tenth part of that used by Régnault, it was only necessary to employ one tenth of the quantity of gas in order to attain as great an in- 
crease of temperature. On account of the saving of material it was possible to give a wider expansion to the research in a comparatively shorter time.

The following Table contains the numbers represented in a somewhat different manner. Columns I., II., and III. contain the true specific heats of the various gases calculated on unit weight. Column IV gives the difference between the true specific heats at $0^{\circ}$ and at $200^{\circ}$, stated in percentages of the specific heat at $0^{\circ}$. The fifth, sixth, and seventh columns give the true specific heats calculated on unit volume, the specific heat of unit volume of air being taken as 0.2389 ; the eighth column shows the specific gravities of the gases; and the ninth contains the proportion, estimated by Régnault, of the products of the volumes $V$ and $\nabla_{1}$ and the pressures $P$ and $P_{1}$, when $P$ is taken as about one atmosphere and $P_{1}$ as about two atmospheres. The deviation of the number so obtained from unity (to which it is equal in the case of perfect gases) may be taken as a measure of the deviation from the state of perfect gas.

\begin{tabular}{|c|c|c|c|c|c|c|c|c|c|}
\hline & \multicolumn{4}{|c|}{ Specific heats of equal weights. } & \multicolumn{5}{|c|}{ Specific heats of equal volumes. } \\
\hline & $\begin{array}{l}\text { I. } \\
0^{\circ} \text {. }\end{array}$ & $\begin{array}{c}\text { II. } \\
100^{\circ} .\end{array}$ & $\begin{array}{l}\text { III. } \\
200^{\circ} .\end{array}$ & IV. & $\begin{array}{l}\text { V. } \\
0^{\circ} .\end{array}$ & $\begin{array}{c}\text { VI. } \\
100^{\circ}\end{array}$ & $\begin{array}{l}\text { VII. } \\
200^{\circ} .\end{array}$ & $\begin{array}{l}\text { VIII. } \\
\text { Speo. } \\
\text { grav. }\end{array}$ & $\begin{array}{c}\mathrm{IX} . \\
\frac{P V}{P_{1} V_{1}}\end{array}$ \\
\hline $\begin{array}{l}\text { Air ............... } \\
\text { Hydrogen .... } \\
\text { Carbonic oxide } \\
\text { Carbonic acid. } \\
\text { Ethylene ....... } \\
\text { Nitrous oxide. } \\
\text { Ammonia...... }\end{array}$ & $\mid \begin{array}{l}0 \cdot 2389 \\
3 \cdot 410 \\
0 \cdot 2426 \\
0 \cdot 1952 \\
0 \cdot 3364 \\
0 \cdot 1983 \\
0 \cdot 5009\end{array}$ & $\begin{array}{c}\cdots \\
\cdots \\
0.2169 \\
0.4189 \\
0.2212 \\
0.5317\end{array}$ & $\begin{array}{c}\ldots \\
\cdots \\
\ldots \\
0 \cdot 2387 \\
0 \cdot 5015 \\
0 \cdot 2442 \\
0.5629\end{array}$ & \begin{tabular}{c|}
0 \\
0 \\
0 \\
$22 \cdot 28$ \\
$49 \cdot 08$ \\
$23 \cdot 15$ \\
$12 \cdot 38$
\end{tabular} & $\mid \begin{array}{l}0.2389 \\
0 \cdot 2359 \\
0 \cdot 2346 \\
0.2985 \\
0.3254 \\
0 \cdot 3014 \\
0.2952\end{array}$ & $\begin{array}{c}\ldots \\
\ldots \\
0.3316 \\
0.4052 \\
0.3362 \\
0.3134\end{array}$ & $\begin{array}{c}\ldots \\
\ldots \\
\ldots \\
0.3650 \\
0.4851 \\
0.3712 \\
0.3318\end{array}$ & $\begin{array}{l}1 \\
0.0692 \\
0.967 \\
1.529 \\
0.9677 \\
1.5241 \\
0.5894\end{array}$ & $\begin{array}{l}1.00215 \\
1 \cdot 00293 \\
1.00722 \\
1.00651 \\
1 \cdot 01881\end{array}$ \\
\hline
\end{tabular}

As, according to Avogadro's law, equal volumes of different gases contain equal numbers of molecules, it follows that the specific heats of equal volumes of gases are also expressive of the molecular heats of these gases.

The specific heats calculated from the foregoing experiments for constant pressure are made up of two parts :--first, the heat connected with the expansion of the gas for overcoming the external pressure, which is calculated (from the coefficient of expansion and equivalent of heat) to be 0.06902 thermal unit for altering the temperature of 1 gram of air through $1^{\circ}$; secondly, the heat connected with the internal work of the gas, which might also be calculated from the estimation of the specific heat at constant volumes. The present does not appear 
to be the time for making an attempt to estimate the separate parts of the heat of molecular motion-heat of atom, and of atoms (atom- und Atomenwärme), according to Naumannwhich constitute the specific heat at constant volume, nor for endeavouring to trace simple relationships between these-inasmuch as these relations would appear altogether different for different temperatures, on account of the unequal alterations in specific heats with alteration in temperature, which are not to be entirely explained as small differences in heats of expansion.

The alterations in the specific heats of gases with alterations in temperature cannot be explained by taking into account the deviations from the state of permanent gases. In the case of ammonia, for instance, the alteration with the temperature is much smaller than it is in the case of nitrous oxide and carbonic acid, although the latter are much more nearly permanent gases than the former, as appears from the proportion of the values of $\frac{\mathrm{PV}}{\mathrm{P}_{\mathbf{1}} \mathrm{V}_{1}}$.

The smallness of the difference between the coefficients of expansion of the gases show that the alterations in question cannot be traced to this difference.

Any attempt to explain the alterations in specific heat of these gases from alterations in the specific heat of the elementary bodies composing them, say carbon and nitrogen, does not appear feasible. For, in the first place, the experiments on air show that the specific heat of nitrogen itself does not alter with the temperature ; and further, the specific heat of all carbon compounds does not show alterations with the temperature. One must rather accept $F$. Weber's view*, that the carbon contained in these compounds is possessed of properties other than those which characterize the carbon of carbonic acid. It is not impossible that variations in the specific heat of carbon may have something to do with the phenomena noticed in the case of carbonic acid.

The alteration in specific heats with the temperature may perhaps be explained by supposing that, when one of the given gases is warmed, a gradual dissociation is taking place which eventually results in a loosening $\dagger$ of the combination of individual atoms, and that this process is attended with the absorption of heat. The fact that the decomposition of nitrous oxide is accompanied with evolution of heat is not opposed to this explanation. Favre regards this evolution of heat as caused by a change of the active oxygen of the oxide into inactive

* Pogg. Ann. 1875, vol. cliv. p. 578; Phil. Mag. [IV.] vol. xliv. p. 300.

+ Horstman, Ber. d. deut. Chem. Ges, ii. 723. 
oxygen. At the temperatures employed in the foregoing researches, however, it is not to be supposed that dissociation would proceed to completion; this change, therefore, would not have taken place.

But further experimental investigations must precede the theoretical discussion of this question. It will be my first endeavour to carry out experiments within greater temperaturelimits, and especially to estimate the specific heats of the vapours. I have already carried out a prolonged series of preliminary experiments with this object, making use of the apparatus already described with a few slight modifications; the narration of these experiments will occupy a further communication.

\section{Model of a small Electrical Machine. By GEORGE Fuller, C.E., Belfast*.}

7 TIS machine is a double-acting electrophorus worked by 1 cranks, with the addition of an arrangement by which a small electric charge given to it is augmented and kept up, so that the dielectric does not require to be recharged.

$A$ is a vulcanite plate supported in a vertical position by two insulated standards, $p, p$.

$\mathrm{B}, \mathrm{B}^{\prime}$ are two insulated metallic plates, one on each side of the plate $\mathrm{A}$; these can be moved together to and from contact with $\mathrm{A}$ by means of cranks worked by the handle $\mathrm{C}$.

$m$ and $n$ are two conductors armed with needles and connected by means of two glass rods, so that they receive the same reciprocal motion from the mechanism by means of the wire, cord, and pulleys, $g, g, g$. The wire $g$ is attached to the arm that moves the plate $\mathrm{B}^{\prime}$; and the length of the cord and size of pulley are so adjusted that when this is in its extreme position from $A$, as shown, $m$ and $n$ are also at one extremity of their motion, as shown; and when $B$ and $B^{\prime}$ are in contact with $A, m$ and $n$ are horizontal. The conductor $n$ is not insulated; and it will be seen by the diagram that $m$ and $n$ during their motion pass on either side of the plate $A$.

To the conductor $m$ is fixed a wire terminating in a brass ball, $d$; this wire is of such length and form that when $B$ and $B^{\prime}$ recede from $A$, and $m$ and $n$ move downwards from their horizontal position, the ball $d$ passes close to $\mathrm{B}^{\prime}$. Care has to be taken that this juxtaposition does not occur until the vulcanite plate separates the points on $m$ and $n$.

The action of the instrument is as follows :-A charge of,

* Communicated by the Physical Society. 